\title{
The Catalytic Activity of Biosynthesized Magnesium Oxide Nanoparticles (MgO-NPs) for Inhibiting the Growth of Pathogenic Microbes, Tanning Effluent Treatment, and Chromium Ion Removal
}

\author{
Ebrahim Saied ${ }^{1}$, Ahmed M. Eid ${ }^{1}{ }^{(}$, Saad El-Din Hassan ${ }^{1, *} \mathbb{D}$, Salem S. Salem ${ }^{1} \mathbb{D}$, Ahmed A. Radwan ${ }^{1}$,

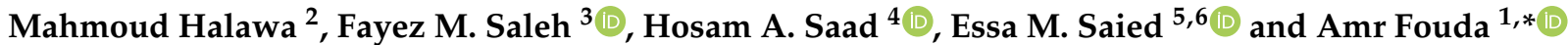

1 Department of Botany and Microbiology, Faculty of Science, Al-Azhar University, Nasr City, Cairo 11884, Egypt; hema_almassry2000@azhar.edu.eg (E.S.); aeidmicrobiology@azhar.edu.eg (A.M.E.); salemsalahsalem@azhar.edu.eg (S.S.S.); ahmedradwan@azhar.edu.eg (A.A.R.)

2 SAJA Pharmaceuticals, 6th of October, Giza 12573, Egypt; mahmoudwaleedh76@gmail.com

3 Department of Medical Microbiology, Faculty of Medicine, University of Tabuk, Tabuk 71491, Saudi Arabia; fsaleh@ut.edu.sa

4 Department of Chemistry, College of Science, Taif University, P.O. Box 11099, Taif 21944, Saudi Arabia; h.saad@tu.edu.sa

check for updates

Citation: Saied, E.; Eid, A.M.; Hassan, S.E.-D.; Salem, S.S.; Radwan, A.A.; Halawa, M.; Saleh, F.M.; Saad, H.A.; Saied, E.M.; Fouda, A. The Catalytic Activity of Biosynthesized Magnesium Oxide Nanoparticles (MgO-NPs) for Inhibiting the Growth of Pathogenic Microbes, Tanning Effluent Treatment, and Chromium Ion Removal. Catalysts 2021, 11, 821. https://doi.org/10.3390/catal11070821

Academic Editors: Beom Soo Kim and Pritam Kumar Dikshit

Received: 28 June 2021

Accepted: 5 July 2021

Published: 6 July 2021

Publisher's Note: MDPI stays neutral with regard to jurisdictional claims in published maps and institutional affiliations.

Copyright: () 2021 by the authors Licensee MDPI, Basel, Switzerland. This article is an open access article distributed under the terms and conditions of the Creative Commons Attribution (CC BY) license (https:// creativecommons.org/licenses/by/ $4.0 /)$.
5 Chemistry Department, Faculty of Science, Suez Canal University, Ismailia 41522, Egypt; saiedess@hu-berlin.de

6 Institute for Chemistry, Humboldt Universität zu Berlin, Brook-Taylor-Str. 2, 12489 Berlin, Germany

* Correspondence: Saad.el-din.hassan@umontreal.ca (S.E.-D.H.); amr_fh83@azhar.edu.eg (A.F.)

Abstract: Magnesium oxide nanoparticles (MgO-NPs) were synthesized using the fungal strain Aspergillus terreus $\mathrm{S} 1$ to overcome the disadvantages of chemical and physical methods. The factors affecting the biosynthesis process were optimized as follows: concentration of $\mathrm{Mg}\left(\mathrm{NO}_{3}\right)_{2} \cdot 6 \mathrm{H}_{2} \mathrm{O}$ precursor $(3 \mathrm{mM})$, contact time $(36 \mathrm{~min}), \mathrm{pH}(8)$, and incubation temperature $\left(35^{\circ} \mathrm{C}\right)$. The characterization of biosynthesized $\mathrm{MgO}-\mathrm{NPs}$ was accomplished using UV-vis spectroscopy, Fourier transform infrared (FT-IR) spectroscopy, transmission electron microscopy (TEM), scanning electron microscopy - energy dispersive X-ray (SEM-EDX), X-ray diffraction (XRD), and dynamic light scattering (DLS). Data confirmed the successful formation of crystallographic, spherical, well-dispersed $\mathrm{MgO}-\mathrm{NPs}$ with a size range of 8.0-38.0 $\mathrm{nm}$ at a maximum surface plasmon resonance of $280 \mathrm{~nm}$. The biological activities of biosynthesized MgO-NPs including antimicrobial activity, biotreatment of tanning effluent, and chromium ion removal were investigated. The highest growth inhibition of pathogenic Staphylococcus aureus, Bacillus subtilis, Pseudomonas aeruginosa, Escherichia coli, and Candida albicans was achieved at $200 \mu \mathrm{g} \mathrm{mL} \mathrm{m}^{-1}$ of MgO-NPs. The biosynthesized MgO-NPs exhibited high efficacy to decolorize the tanning effluent $\left(96.8 \pm 1.7 \%\right.$ after $150 \mathrm{~min}$ at $\left.1.0 \mu \mathrm{g} \mathrm{mL}^{-1}\right)$ and greatly decrease chemical parameters including total suspended solids (TSS), total dissolved solids (TDS), biological oxygen demand (BOD), chemical oxygen demand (COD), and conductivity with percentages of 98.04, 98.3, 89.1, 97.2, and 97.7\%, respectively. Further, the biosynthesized MgO-NPs showed a strong potential to remove chromium ions from the tanning effluent, from $835.3 \mathrm{mg} \mathrm{L}^{-1}$ to $21.0 \mathrm{mg} \mathrm{L}^{-1}$, with a removal percentage of $97.5 \%$.

Keywords: biogenic synthesis; Aspergillus terreus; tanning effluent; chromium ion; pathogenic microbes; nanoparticle characterization

\section{Introduction}

Environmental and water pollution dramatically increase due to industrial development, populational growth, and energy production [1]. These pollutants are considered the main factors for disease, illness, and death due to their toxicity, non-degradability, and tendency to accumulate in the food chain [2]. The different industrial activities are the main 
sources of contaminated wastewater because they produce highly toxic waste that has a long-term negative impact [3,4]. The tannery and leather sectors are considered the largest industries that use hazardous chemical compounds and require a high amount of water [5]. These sectors produce high amounts of effluents containing highly toxic compounds and are characterized by increase total dissolved solids (TDS), total suspended solids (TSS), conductivity, chemical oxygen demand (COD), and biochemical oxygen demand (BOD) [6]. Therefore, the tanning and leather effluents require extra treatment before discharge into the eco-system. Chromium is considered one of the most widely used heavy metals in the tanning and leather industry and is widely discharged as part of the effluent [7]. Further, chromium is incorporated into electroplating and paint manufacturing, resulting in large quantities being discharged into the environment [8]. Moreover, the development of new compounds to overcome the resistance properties of microbes to different antibiotic is the main goal for investigators $[9,10]$.

Nanotechnology sciences provide a promising tool for the synthesis of new active compounds with superior properties to be breakthrough applications in various biomedical and biotechnological sectors [11,12]. Among these new nanoparticles, magnesium oxide nanoparticles (MgO-NPs) are characterized by excellent optical, thermal, mechanical, and chemical properties [13]. MgO-NPs have high reactivity due to the presence of highly reactive edges and a high surface area [14]. Therefore, MgO-NPs have a variety of applications in various fields such as catalyst supports, agricultural products, paints, superconductor products, antimicrobial materials, photonic devices, sensors, and adsorbents [15-17]. Notably, MgO-NPs have antibacterial properties against harmful microbes, for instance, $S$. aureus and E. coli $[18,19]$. Further, they can be utilized as adsorbent materials due to the high removal efficiency [20]. MgO-NPs act as excellent adsorbents for various chemical species and this property increases with a decrease in $\mathrm{MgO}$ size [21]. Recently, $\mathrm{MgO}$ nanoparticles have obtained popularity in environmental science due to their fascinating and intrinsic properties [22].

Several chemical and physical methods have been used to fabricate $\mathrm{MgO}-\mathrm{NPs}$ such as chemical precipitation, thermal decomposition, sol-gel, combustion, and chemical vapor deposition $[13,23]$. These methods predominantly require several processing steps, controlled $\mathrm{pH}$, high temperature and pressure, expensive equipment, and toxic chemicals. These techniques produce numerous by-products that may be toxic to ecosystems. Therefore, there is a need to develop a low-cost, eco-friendly method for nanoparticle synthesis [11]. Recently, the biogenic synthesis of NPs has a wide range of interest because of the reduction or elimination of toxic substances that are present in the environment from chemical and physical methods [24]. Microorganisms such as fungi, yeast, actinomycetes, and bacteria can reduce metal and their oxides to NPs. The biogenic synthesis of NPs using fungi (eukaryotic organisms) has numerous advantages over the prokaryotic organisms, e.g., easy to multiply, grow, handle, and downstream process for nano-biosynthesis [25].

In the present study, we have tried to explore a rapid, cost-effective, eco-friendly method for fabricating MgO-NPs using the fungal strain Aspergillus terreus S1. The optimized biosynthesis process was investigated by studying the effect of metal precursors, incubation temperature, $\mathrm{pH}$, and contact time. The biogenically synthesized MgO-NPs were characterized using various techniques consisting of UV-vis spectroscopy, X-Ray diffraction (XRD), scanning and energy dispersive X-Ray spectroscopy (SEM-EDX), transmission electron microscopes (TEM), dynamic light scattering (DLS), and Fourier-transform infrared spectroscopy (FT-IR). The efficacy of biosynthesized MgO-NPs to inhibit the growth of different pathogenic bacterial and fungal strains was assessed. Moreover, utilizing MgONPs for decolorization and treatment of tanning effluent and removal of heavy metals are among the main goals. 


\section{Results and Discussion}

\subsection{Isolation and Identification of the Fungal Isolates}

In the current study, five fungal isolates were obtained from cultivated soil samples; we selected fungal isolate $\mathrm{S} 1$ for MgO-NPs based on its best and rapid NP synthesis. The selected fungal isolate underwent primary identification using morphological and microscopic analysis. Original identification was done according to standard keys based on morphological and cultural characteristics. The fungal isolate appears brownish, with compact conidial heads, biseriate, and densely columnar. Conidiophores are smooth and hyaline. The conidia are small, about $2 \mu \mathrm{m}$ in diameter, globose-shaped, and smooth-walled. According to morphological and cultural characterization, the fungal isolate S1 belongs to Aspergillus sp. [26,27]. The primary identification was confirmed by amplification and sequencing of the internal transcribed spacer (ITS) gene. The sequence analysis revealed that the fungal strain $\mathrm{S} 1$ is strongly related to Aspergillus terreus (accession number: MT558939) with a similarity percentage of $93 \%$. The fungal strain obtained in this study was identified as Aspergillus terreus strain S1 (Figure 1). The sequence analysis acquired from the current study was deposit in GenBank under accession number MW774586.

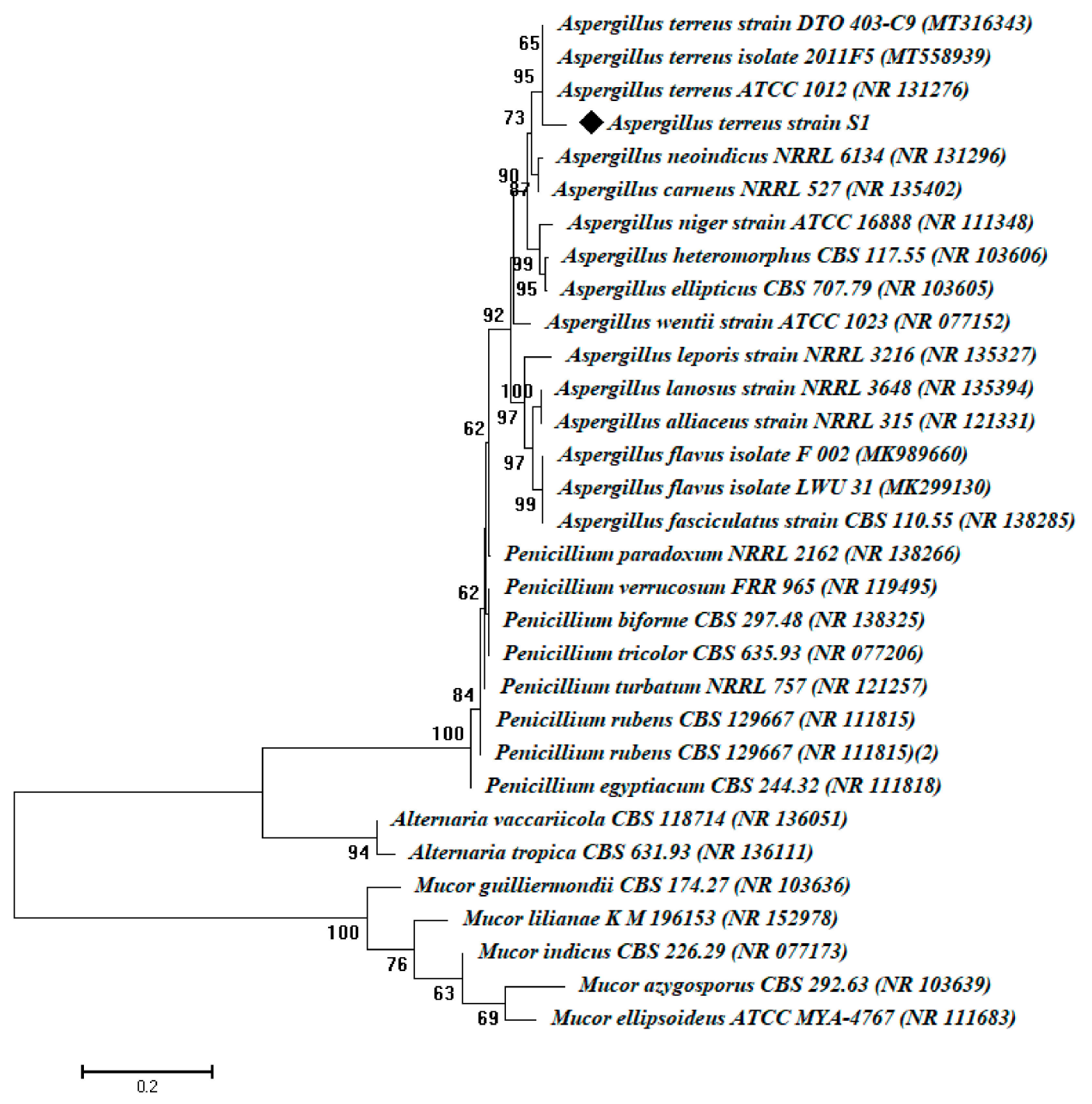

Figure 1. Phylogenetic tree of the fungal strain S1 with the sequences from NCBI. The symbol $\downarrow$ refers to ITS fragments retrieved from this study. The tree was constructed with MEGA 6.1 using the neighbor-joining method. 
Aspergillus terreus has been characterized by its high secretion of various secondary metabolites such as chemicals (i.e., terrein, terreic acid, and terretonin), enzymes (Lipase, amylase, and reductase), fermentative compounds (i.e., polyketide compounds), and a wide range of by-products [28-30]. These various metabolites enable faster incorporation of $A$. terreus into various biotechnological applications. Therefore, we can benefit from these metabolites in the green synthesis of metal and metal oxide nanoparticles. Interestingly, A. terreus was utilized as a biocatalyst for the green synthesis of zinc, titanium, and magnesium nanoparticles [31].

\subsection{Biogenic Synthesis of $\mathrm{MgO}-\mathrm{NPS}$}

Metal and metal oxide nanoparticle synthesis by biological approaches can be used as an alternative to chemical and physical methods [32]. This phenomenon can be attributed to the advantages of biological synthesis such as the cost, the environmentally friendly nature, biocompatibility, scalability, and the avoidance of harsh synthesis conditions such as high temperature and $\mathrm{pH}$ [11]. Among biological entities, fungi can be identified as a promising tool for biogenic nanoparticle synthesis because of diverse metabolites and high metal tolerances [33]. Proteins and enzymes secreted by A. terreus strain $\mathrm{S} 1$ have an important role in the reduction of $\mathrm{Mg}\left(\mathrm{NO}_{3}\right)_{2} \cdot 6 \mathrm{H}_{2} \mathrm{O}$ to $\mathrm{MgO}-\mathrm{NPs}$ and confer capping and stabilization features [31,34].

The initial observation for successful MgO-NP production is the color change from colorless to turbid white after stirring $\mathrm{Mg}\left(\mathrm{NO}_{3}\right)_{2} \cdot 6 \mathrm{H}_{2} \mathrm{O}$ with biomass filtrate. This change can be attributed to the role of $A$. terreus-secreted metabolites in the reduction of $\mathrm{NO}_{3}{ }^{-}$to $\mathrm{NO}_{2}$ and then the reduction of $\mathrm{Mg}^{2+}$ to $\mathrm{Mg}(\mathrm{OH})_{2}$ by liberated electrons. The as-formed $\mathrm{Mg}(\mathrm{OH})_{2}$ was calcinated at $400{ }^{\circ} \mathrm{C}$ to form MgO-NPs [35].

The production of MgO-NPs was confirmed by measuring the maximum surface plasmon resonance (SPR) by UV-Vis spectroscopy. The morphological characteristics (size and shape), as well as distribution of biogenically synthesized NPs, are usually correlated with SPR [36]. In this respect, Nguyen et al. [37] reported that the size of biogenic MgO-NPs was smaller or larger according to $300 \leq \mathrm{SPR} \geq 300$. In the current study, the maximum SPR value of biogenic MgO-NPs was detected at a wavelength of $280 \mathrm{~nm}$ (Figure 2), which confirms the formation of particles at the nanoscale. Further, the MgO-NPs synthesized by different extracts (flower, bark, leaf) of Tecoma stans (L.) showed maximum SPR peaks at $281 \mathrm{~nm}$ [37]. Moreover, the maximum absorption band of MgO-NPs synthesized by the floral extract of Matricaria chamomilla L. was observed at $230 \mathrm{~nm}$ [38].

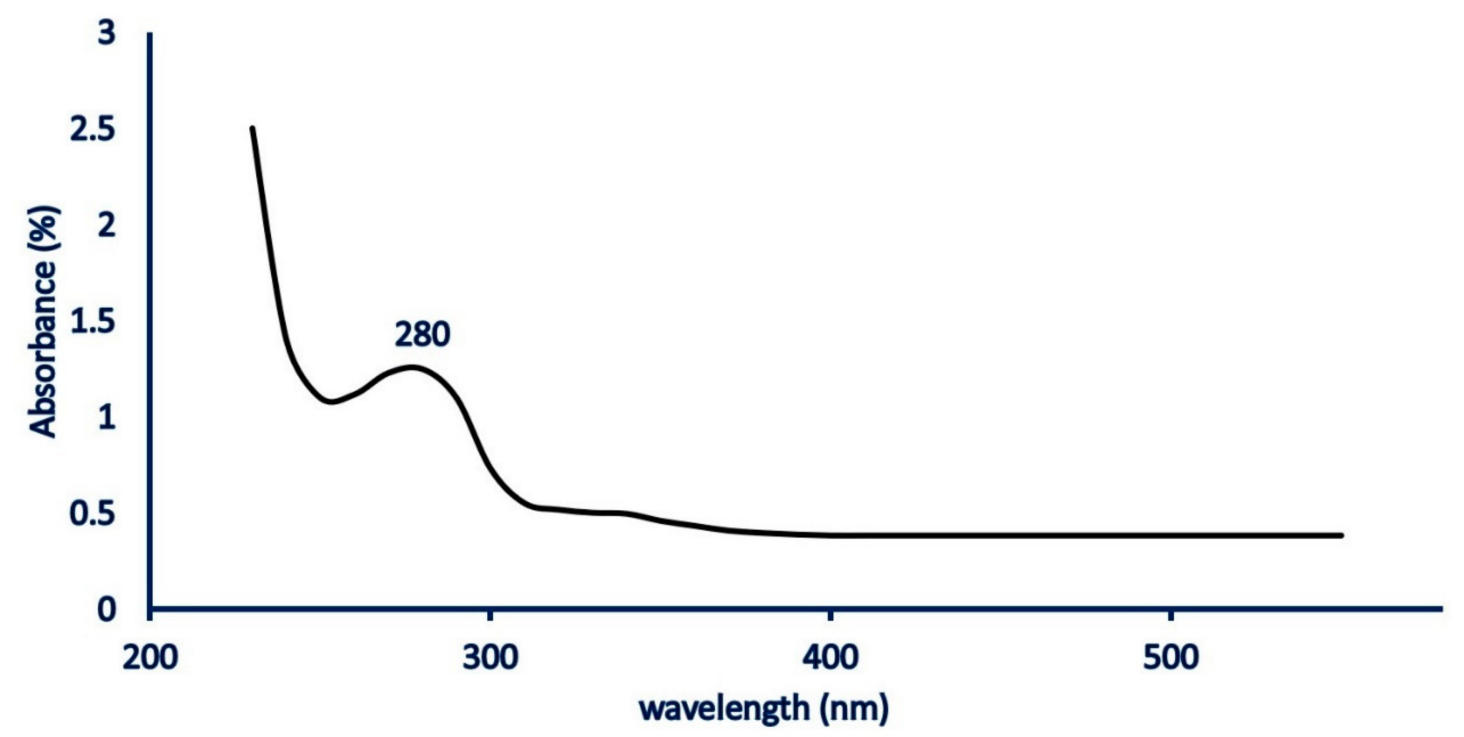

Figure 2. UV-Vis spectroscopy of myco-synthesized MgO-NPs showed maximum SPR at $280 \mathrm{~nm}$. 


\subsection{Optimizing Biosynthesized MgO-NPs}

The stability and biological activity of biogenic nanoparticles are usually influenced by environmental factors such as precursor concentration, contact time or incubation time, $\mathrm{pH}$ values, and incubation temperature. The investigated factors have various impacts on fungal-secreted metabolites such as enzymes, proteins, carbohydrates, and hence the reducing and stabilizing processes are affected [39]. Therefore, the optimization of these environmental factors will decrease the times required for biosynthesis, increase the NP stability, reduce the NP agglomeration, and finally support the productivity [40].

The activity of reducing agents differs according to the metal precursor concentration. In the current study, the absorbance band at $\lambda \max _{280}$ was increased by increasing the precursor concentration, and the maximum absorbance was achieved at $3 \mathrm{mM}$. By increasing the $\mathrm{Mg}\left(\mathrm{NO}_{3}\right)_{2} \cdot 6 \mathrm{H}_{2} \mathrm{O}$ concentration up to $3 \mathrm{mM}$, the absorbance was decreased (Figure 3A). According to obtained data, the fungal metabolites exhibited the optimum reduction of the metal precursor at $3 \mathrm{mM}$, whereas above and below this concentration, the biosynthesized MgO-NPs aggregated and hence decreased the absorbance band [41]. Muangban and Jaroenapiba [42] reported that tungsten oxide nanofibers tended to agglomerate by increasing the metal precursor concentration because of increasing nanoparticle size. Further, Jeevanandam et al. [43] study the effect of $\mathrm{Mg}\left(\mathrm{NO}_{3}\right)_{2} \cdot 6 \mathrm{H}_{2} \mathrm{O}$ concentration on the average particle size of MgO-NPs synthesized by Aloe barbadensis aqueous extract. It can be concluded that an increase in the concentration of the metal precursor leads to increased nanoparticle size and hence an increase in NP aggregation.
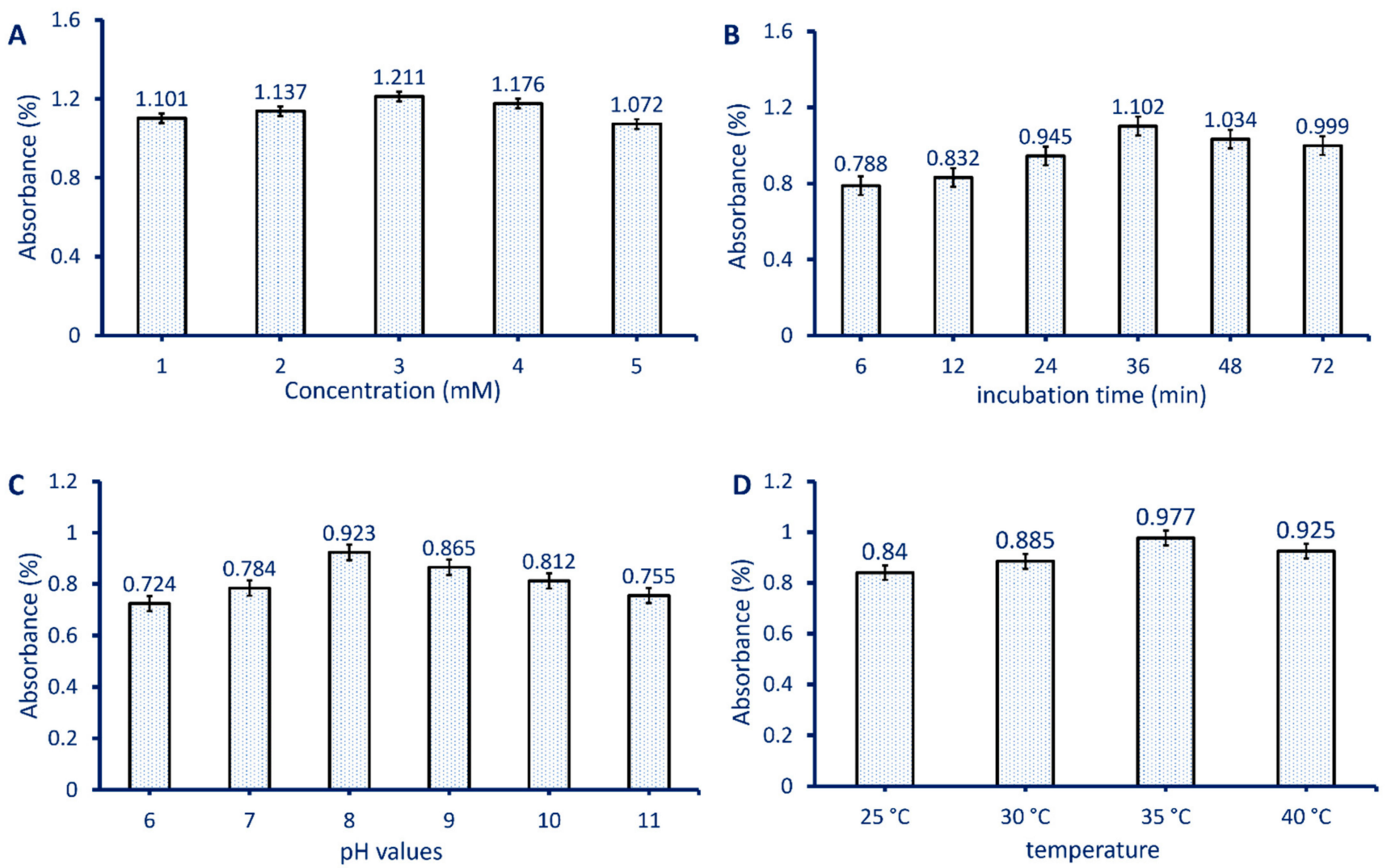

Figure 3. Optimizing factors for biogenic MgO-NPs using A. terreus strain S1. (A) denotes the different $\mathrm{Mg}\left(\mathrm{NO}_{3}\right)_{2} \cdot 6 \mathrm{H}_{2} \mathrm{O}$ concentrations; (B) denotes the contact time between biomass filtrate and optimum $\mathrm{Mg}\left(\mathrm{NO}_{3}\right)_{2} \cdot 6 \mathrm{H}_{2} \mathrm{O}$ concentration; (C) illustrates the effect of $\mathrm{pH}$ values, and (D) denotes the effect of incubation temperature on biogenic MgO-NPs.

The contact time or reaction time between the fungal biomass filtrate and optimum $\mathrm{Mg}\left(\mathrm{NO}_{3}\right)_{2} \cdot 6 \mathrm{H}_{2} \mathrm{O}$ concentration $(3 \mathrm{mM})$ is considered a critical factor affecting the biogenic synthesis of MgO-NPs. The intensity of the color that formed was monitored by detecting 
the maximum absorbance band at $\lambda \max _{280}$. Data illustrated in Figure 3B show that the optimum contact time between the metal precursor and fungal biomass filtrate was $36 \mathrm{~min}$. At this time, the maximum color intensity was achieved because a large number of metal ions were reduced. On the other hand, the absorbance intensity was decreased by increasing contact time due to the aggregation of some MgO-NPs, and then the color intensity and particle size were reduced. Moreover, in the early contact time stages, the low number of metal ions was reduced and hence the SPR peak appeared broader [44,45]. Compatible with our study, the optimum contact time for the biogenic synthesis of MgO-NPs by Aloe barbadensis plant extract was $30 \mathrm{~min}$ [43]. Synthesis by chemical and physical methods such as microemulsion, sol-gel, co-precipitation, and solvothermal methods required a contact time of more than $48 \mathrm{~min}$ [46].

The effect of different $\mathrm{pH}$ values ranging between 6 and 11 on the biogenic synthesis of MgO-NPs by Aspergillus terreus strain S1 was shown (Figure 3C). Data analysis showed that the highest absorbance at $\lambda \max _{280}$ was accomplished at $\mathrm{pH} 8$, which is evidence of maximum MgO-NP production. This behavior could be attributed to the stabilizing fungal metabolites including proteins and enzymes secreted by Aspergillus terreus strain $\mathrm{S} 1$ in an alkaline medium [47]. The metabolites present in the biomass filtrate of $A$. carbonarious D-1 were more active to reduce $\mathrm{FeCl}_{3} \cdot 6 \mathrm{H}_{2} \mathrm{O}$ and $\mathrm{Mg}\left(\mathrm{NO}_{3}\right)_{2} \cdot 6 \mathrm{H}_{2} \mathrm{O}$ to fabricate $\alpha-\mathrm{Fe}_{2} \mathrm{O}_{3}-\mathrm{NPs}$ and MgO-NPs in an alkaline medium [48].

The activity of reducing agents involved in the biomass filtrate of $A$. terreus strain $\mathrm{S} 1$ is correlated with the incubation temperature. Therefore, it is important to detect the optimum temperature required for reducing, capping, and stabilizing MgO-NPs. In the current study, the effects of different incubation temperatures $\left(25-40{ }^{\circ} \mathrm{C}\right)$ on the color intensity and hence biogenic MgO-NPs synthesis were investigated. Data showed that the metabolites involved in the $A$. terreus biomass filtrate were highly active as reducing agents at $35^{\circ} \mathrm{C}$ (Figure 3D). The absorbance intensity was decreased at a temperature of more or less than $35^{\circ} \mathrm{C}$. This was attributed to the enzymes and proteins being more stable at this temperature. Hassan et al. [41] reported that the biomass filtrate of Rhizopus oryaze was more stable at an incubation temperature of $35^{\circ} \mathrm{C}$ during $\mathrm{MgO}$ nanoparticle synthesis. Moreover, the size, shape, and stability of nanoparticles are correlated with the incubation temperature [43]. Interestingly, increasing the incubation temperature will lead to a higher diffusion coefficient, which decreases the reaction time needed to form stable particles and hence decreases the induction time [49].

\subsection{Characterizations of Biogenically Synthesized MgO-NPs}

\subsubsection{Fourier Transform Infrared (FT-IR) Spectroscopy}

FT-IR analysis is a powerful technique used for identifying the possible functional groups in the biomass filtrate of $A$. terreus strain $\mathrm{S} 1$ that are responsible for the reduction of metal precursors to form MgO-NPs [50]. FT-IR analysis scans at a wavenumber between 400 to $4000 \mathrm{~cm}^{-1}$ as shown in Figure 4 . The result showed that several intense absorption peaks appeared at 3700, 3420, 2850, 2727, 2398, 1630, 1370, 1027, and $520 \mathrm{~cm}^{-1}$. The peak observed at $3700 \mathrm{~cm}^{-1}$ signifies the $-\mathrm{OH}$ stretching band [51]. The broad peak at $3420 \mathrm{~cm}^{-1}$ corresponds to hydrogen bonds arising from $\mathrm{NH}_{2}$ and $\mathrm{OH}$ groups in protein molecules [52]. The peaks observed at 2850,2727, and $2398 \mathrm{~cm}^{-1}$ may correspond to the $\mathrm{C}-\mathrm{H}$ stretching of methylene groups of proteins. The medium peaks observed at $1630 \mathrm{~cm}^{-1}$ correspond to the bending mode of primary amine $(\mathrm{N}-\mathrm{H})$ overlapped with either amide or carboxylate salt. The medium peak at $1370 \mathrm{~cm}^{-1}$ can be related to $\mathrm{C}-\mathrm{H}$ bending vibrations of the aromatic tertiary amine group $[53,54]$, whereas the peak at $1027 \mathrm{~cm}^{-1}$ matched the $\mathrm{Mg}-\mathrm{OH}$ stretching [55] with the C-H out-of-plane bend. The peaks that appear between wavenumber $400-700 \mathrm{~cm}^{-1}$ confirm the presence of $\mathrm{MgO}$ at the nanoscale $[51,53,56]$. The peaks observed in FT-IR spectra reflect the capacity of metabolites present in the $A$. terreus strain $\mathrm{S} 1$ biomass filtrate to reduce, cap, and stabilize MgO-NPs. 


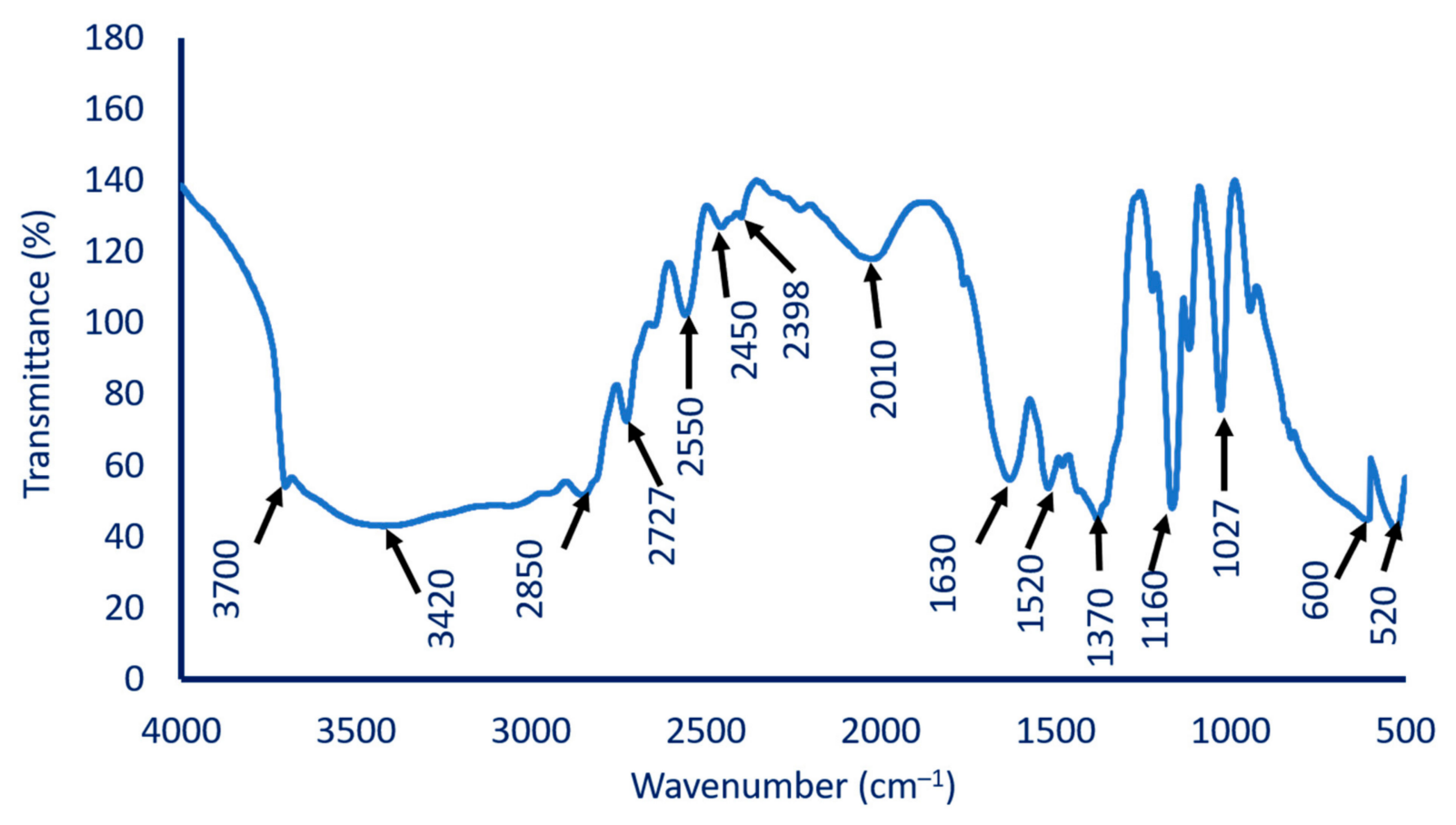

Figure 4. The FT-IR spectrum of myco-synthesized MgO-NPs fabricated by metabolites of $A$. terreus strain S1.

\subsubsection{Transmission Electron Microscopy}

TEM analysis was carried out to determine the approximate size and shape of the $A$. terreus-mediated MgO-NPs biosynthesized. Data illustrated in Figure 5A showed that the biogenic MgO-NPs synthesized by harnessing metabolites of $A$. terreus strain $\mathrm{S} 1$ had a spherical shape and well-dispersed narrow-sized particles surrounded with capping proteins and enzymes. TEM image measurement revealed that the sizes of biogenic MgO-NPs ranged between 8.0 and $38.0 \mathrm{~nm}$ with an average diameter of $19.91 \pm 9.9 \mathrm{~nm}$ (Figure 5B). In our recent study, Aspergillus carbonarious D-1 mediated green synthesis of spherical MgO-NPs with an average size of 20-80 nm [48]. Compatible with our study, the particle size of spherical MgO-NPs synthesized by Aspergillus terreus TFR was $10 \mathrm{~nm}$ with a PDI value of 0.236 and $100 \%$ conversion of the precursor compound into nanoparticles [31]. Moreover, the plant extract of Pisidium guvajava and Aloe vera mediated biosynthesis of MgO-NPs with an average size range of $50 \mathrm{~nm}$ [57]. It is well known from previously published studies that the biological activity of NPs is increased by decreasing the average size [58,59]. The growth inhibition percentages of Bacillus subtilis after treatment with different sizes of biosynthesized MgO-NPs ( $35.9 \mathrm{~nm}, 47.3 \mathrm{~nm}$, and micron size $2145.9 \mathrm{~nm}$ ) were $96.1 \%$, $94.5 \%$, and $75.7 \%$, respectively [60]. In this study, the size of fabricated MgO-NPs was small $(8.0-39.0 \mathrm{~nm})$, and we therefore predicted their integration in different biomedical and biotechnological applications. 

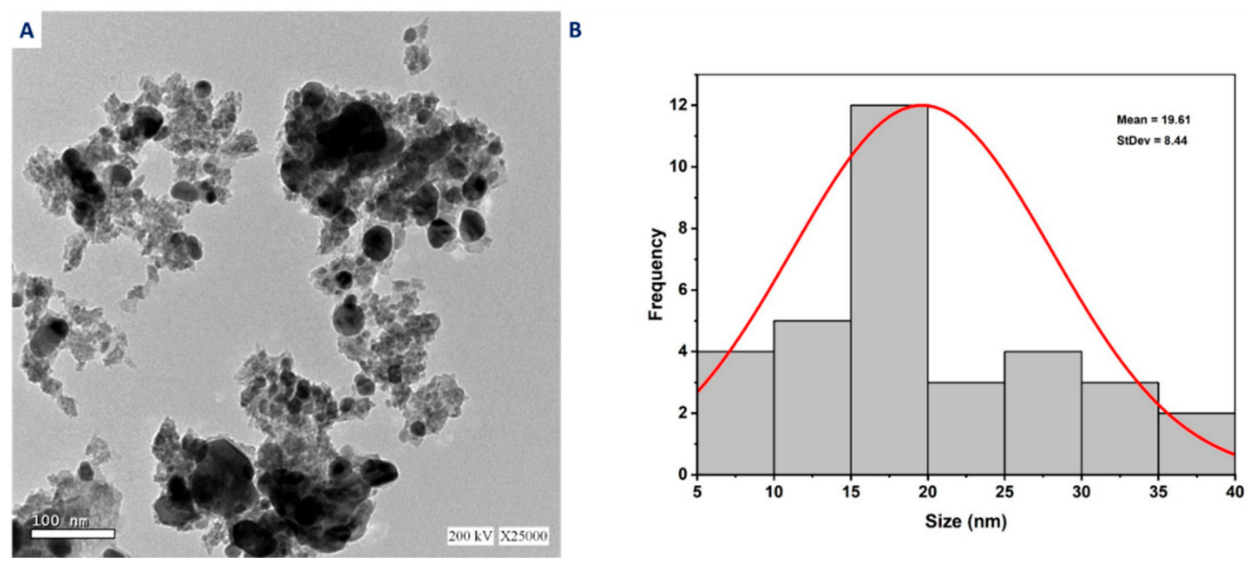

Figure 5. Characterization of MgO-NPs synthesized by A. terreus strain S1, (A) TEM image; (B) size distribution according to the TEM image.

\subsubsection{Scanning Electron Microscopy—Energy Dispersive X-ray (SEM-EDX)}

The SEM-EDX analysis is considered a useful technique to study the topographical structure of biosynthesized MgO-NPs, aggregation, and chemical compositions. As seen in Figure 6A the MgO-NPs synthesized by A. terreus strain S1 were well-dispersed and spherical. Moreover, the presence of $\mathrm{Mg}$ and $\mathrm{O}$ ions in the sample was confirmed by the EDX profile. Data showed that the weight percentages of $\mathrm{Mg}$ and $\mathrm{O}$ were $18.3 \%$ and $28.1 \%$, respectively, whereas the atomic percentages were $10.9 \%$ and $25.8 \%$, respectively (Figure 6B). Further, the successful fabrication of $\mathrm{MgO}-\mathrm{NPs}$ was confirmed by the presence of a $\mathrm{Mg}$ peak at an energy of 0.5 to $1.5 \mathrm{KeV}$ [53] as shown in Figure 6B.
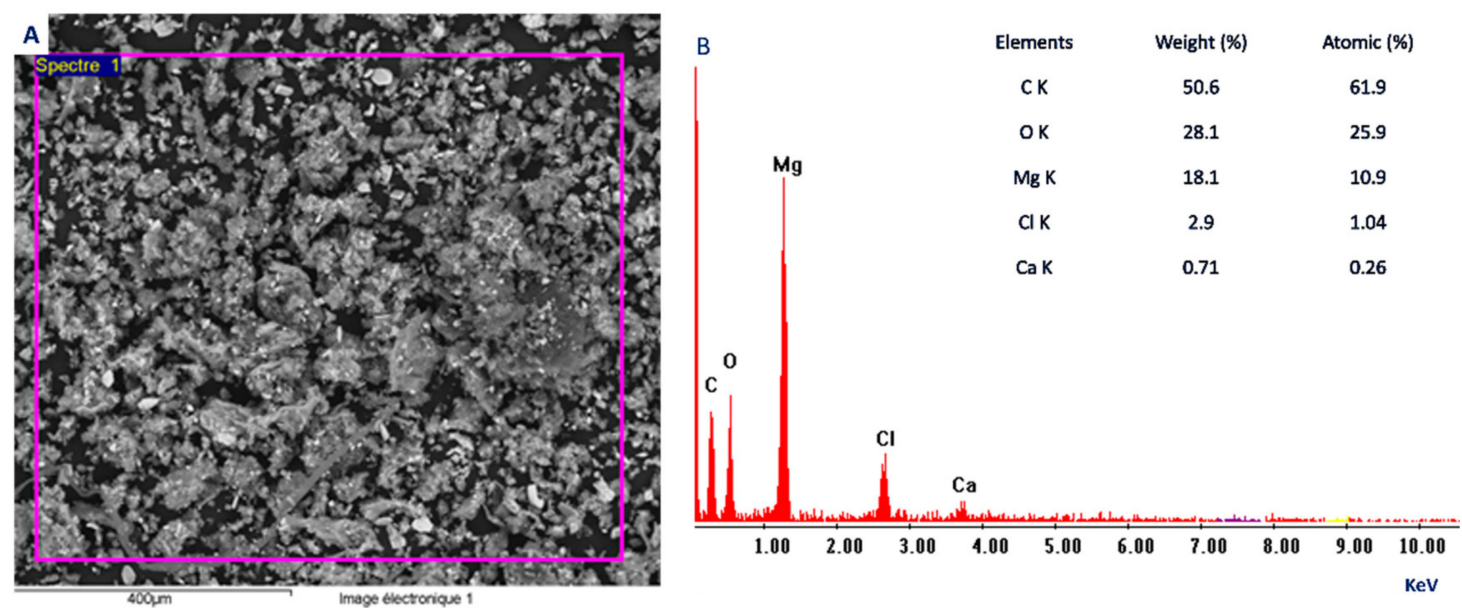

Figure 6. Characterization of MgO-NPs synthesized by A. terreus strain S1, (A) SEM image; (B) EDX profile.

On the other hand, other elements, $\mathrm{C}, \mathrm{Cl}$, and $\mathrm{Ca}$, in the $\mathrm{MgO}-\mathrm{NP}$ sample were detected by EDX profiles with weight percentages of $50.6 \%, 2.49 \%$, and $0.71 \%$, respectively. The presence of these additional peaks indicates the presence of some impurities in the sample, which was confirmed by XRD analysis. Some investigators attributed the presence of additional peaks in the EDX profile to the hydrolysis of enzymes, proteins, and other fungal metabolites that act as capping and stabilizing agents by X-ray [61].

\subsubsection{X-ray Diffraction (XRD) Analysis}

The crystallographic structure of optimized MgO-NPs was studied using XRD analysis. XRD spectra (Figure 7A) showed major five intense peaks at $2 \theta$ values of $36.94^{\circ}$ (111), $42.68^{\circ}(200), 62.4^{\circ}(220), 74.28^{\circ}(311)$, and $78.62^{\circ}(222)$. The identified diffraction peaks 
matched well with the crystallographic structure according to JCPDS standard (JCPDS file No. 89-7746) [62]. The presence of fine additional peaks in XRD spectra confirms data obtained by EDX analysis, i.e., the sample contained some impurities. According to XRD spectra, oxides represented by $\mathrm{Mg}(\mathrm{OH})_{2}$ and $\mathrm{MgO}$ existed in the biosynthesized sample. The observed peaks at $2 \theta^{\circ}$ of $36.9^{\circ}(111), 75.08^{\circ}$ (311), and $78.64^{\circ}$ (222) corresponded to $\mathrm{Mg}(\mathrm{OH})_{2}$, whereas, the diffraction peaks at $2 \theta^{\circ}$ of $42.16^{\circ}(200)$, and $62.6^{\circ}(220)$ signified cubic MgO-NPs [37]. The average crystallite size can be calculated according to XRD analysis using the Debye-Scherrer equation, which was found to be $<20 \mathrm{~nm}$.
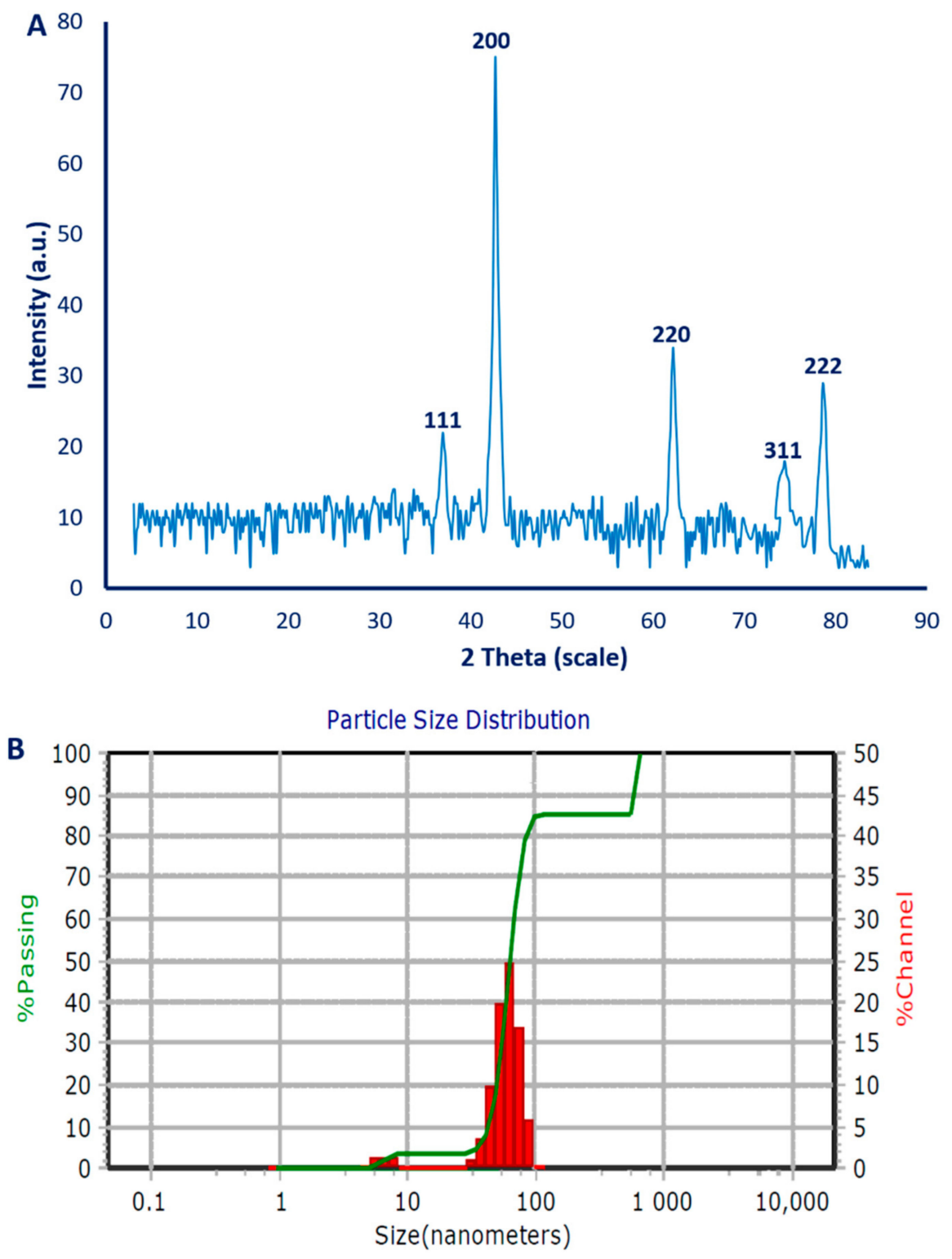

Figure 7. (A) The XRD analysis of the crystallographic structure; (B) the DLS analysis of biogenically synthesized MgO-NPs.

\subsubsection{Dynamic Light Scattering (DLS)}

The DLS technique is used to investigate the size and dispersion of MgO-NPs in the colloidal solution through a reaction of light beams with biogenically synthesized MgO-NPs [63]. In the current study, the average size of biogenic MgO-NPs was $40.6 \mathrm{~nm}, 60.1 \mathrm{~nm}$, and $5.6 \mathrm{~nm}$ for volume intensities of $10 \%, 81.3 \%$, and $8.7 \%$ of the colloidal solution (Figure $7 \mathrm{~B}$ ). As shown from the DLS analysis, the size of MgO-NPs was larger than that acquired from other techniques such as TEM and XRD. This is attributed to the coating agent that capped and 
stabilized the surface of NPs [64,65]. Furthermore, the larger size from DLS may be due to the non-homogenous NP distribution in colloidal solution [66]. Moreover, the Solvation spheres around the nanoparticles may be a factor for the size increase.

The polydispersity index (PDI) refers to the homogeneity percentages of NPs in the colloidal solution. The homogeneity percentages are increased or decreased when the PDI value is lower than or higher than 0.4 , respectively. On the other hand, the NP colloidal solution is heterogenous when the PDI value $\geq 1$. The obtained data demonstrated that the PDI value of MgO-NPs synthesized by the A. terreus strain S1 was 0.2 , which indicates the high homogeneity of the colloidal solution.

\subsection{Antimicrobial Activity}

The activity of biogenically synthesized MgO-NPs to inhibit the growth of pathogenic Gram-positive bacteria represented by Staphylococcus aureus, Bacillus subtilis, Gram-negative bacteria including Pseudomonas aeruginosa, and Escherichia coli, and unicellular fungi of Candida albicans was studied by the agar well-diffusion method. Analysis of variance showed that the antimicrobial activity of MgO-NPs against selected pathogenic microbes was dependent on the concentration; the activity increased by increasing the NP concentration. The obtained data are compatible with published investigations about the relationship between the activity of NPs and their concentrations [57,59,67]. Results showed that the biogenic MgO-NPs synthesized by A. terreus strain S1 exhibited antimicrobial activity at $200 \mu \mathrm{g} \mathrm{mL} \mathrm{m}^{-1}$ against all tested pathogenic microbes as follows: C. albicans $(12.8 \pm 0.3 \mathrm{~mm})$, E. coli $(11.3 \pm 0.6 \mathrm{~mm})$, P. aeruginosa $(14.7 \pm 1.9 \mathrm{~mm})$, S. aureus $(11.3 \pm 0.6 \mathrm{~mm})$, and $B$. subtilis (13.3 $\pm 1.9 \mathrm{~mm}$ ) (Figure 8). Recently, MgO-NPs synthesized by Rhizopus oryaze E3 showed antimicrobial activity with varied ZOIs, e.g., B. subtilis (11.5 $\pm 0.5 \mathrm{~mm})$, S. aureus $(10.6 \pm 0.4 \mathrm{~mm})$, E. coli $(14.3 \pm 0.7 \mathrm{~mm})$, P. aeruginosa $(13.7 \pm 0.5 \mathrm{~mm})$, and C. albicans $(14.7 \pm 0.6 \mathrm{~mm})$ at a concentration of $200 \mu \mathrm{g} \mathrm{mL} \mathrm{mL}^{-1}$ [41]. Moreover, a Swertia chirayaita plant extract mediated the green synthesis of MgO-NPs with antibacterial activity against $S$. aureus, E. coli, and S. epidermidis, with ZOIs of 14, 15, and $12 \mathrm{~mm}$, respectively [18].

The minimum inhibitory concentration (MIC) is defined as the lowest concentration of an active substance that inhibits microbial growth. It is important to detect MIC values for active compounds against pathogenic microbes especially if these compounds are integrated into biomedical applications. To achieve this goal in the current study, the activity of different concentrations $\left(150,100,50\right.$, and $\left.25 \mu \mathrm{g} \mathrm{mL}^{-1}\right)$ of MgO-NPs was investigated. Data analysis showed that the MIC value for P. aeruginosa was $50 \mu \mathrm{g} \mathrm{mL} \mathrm{m}^{-1}$ with a ZOI of $8.3 \pm 0.3 \mathrm{~mm}$, whereas E. coli, C. albicans, S. aureus, and B. subtilis had an MIC value of $100 \mu \mathrm{g} \mathrm{mL}^{-1}$ with ZOIs of $8.0 \pm 0.0,8.7 \pm 0.9,8.0 \pm 0.0$, and $9.3 \pm 0.6 \mathrm{~mm}$, respectively (Figure 8 ).

The inhibitory effect of biogenic MgO-NPs can be attributed to different mechanisms such as (1) producing reactive oxygen species (ROS), (2) interaction between MgO-NPs and microbial cell walls that ultimately lead to cell death, (3) discharge of $\mathrm{Mg}^{2+}$ ions into the cell, and (4) alkaline effects of $\mathrm{MgO}$ on the microbial cell [68-70]. In the current study, Gram-negative $P$. aeruginosa was the most sensitive microorganism toward biosynthesized $\mathrm{MgO}-\mathrm{NPs}$, and this phenomenon can be attributed to differences in cell wall structures between Gram-positive and Gram-negative bacteria. The cell wall of Gram-positive bacteria is characterized by a thick layer of peptidoglycan in contrast to Gram-negative bacteria that have a thin layer of peptidoglycan plus lipopolysaccharides (LPS). The positive charge of NPs is strongly attracted to the LPS-negative charge, and hence it is the deposit on the bacterial cell membrane that ultimately disrupts selective permeability [71]. Moreover, $\mathrm{MgO}-\mathrm{NPs}$ can stop the communication tools, which is quorum sensing between microbial strains, and hence the physiological functions and various microbial activities fail to continue $[72,73]$. 


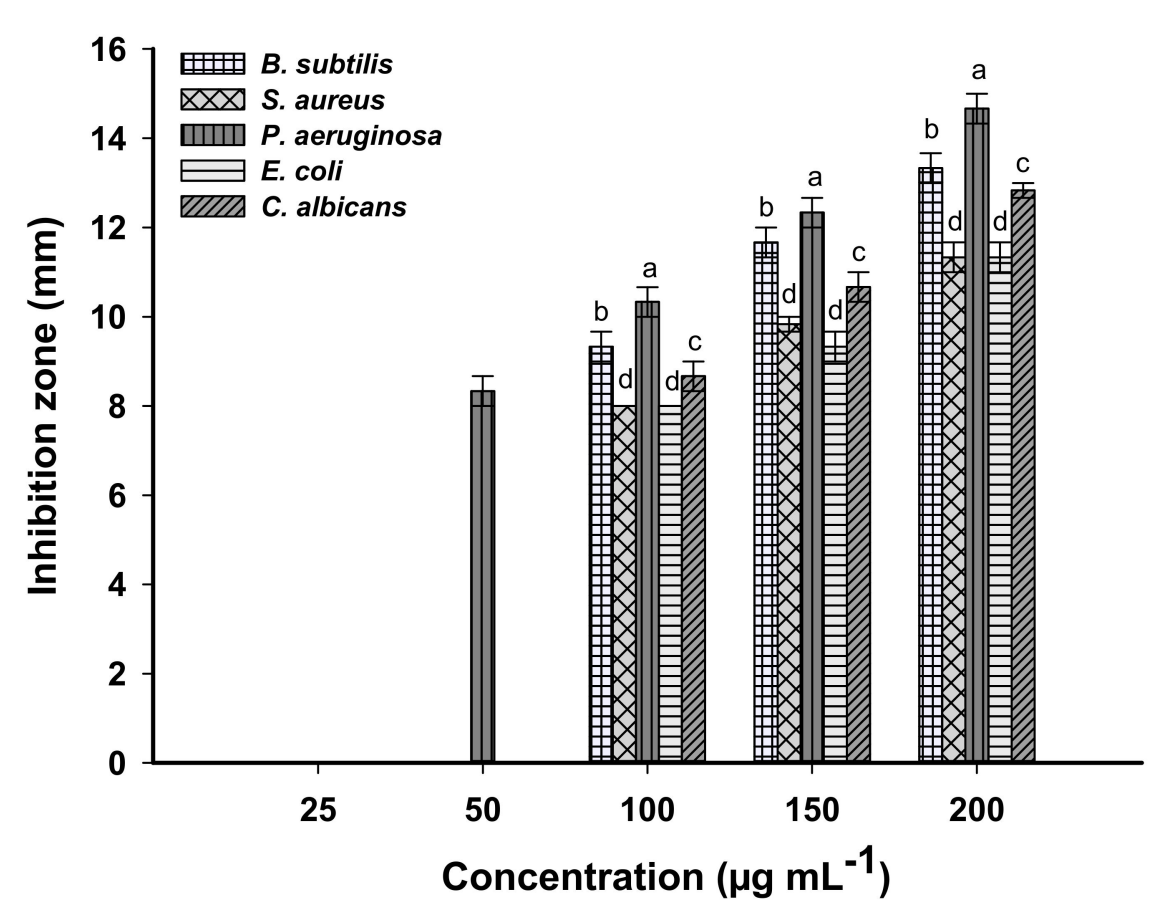

Figure 8. The antimicrobial activity of different concentrations of biogenically synthesized MgO-NPs against Staphylococcus aureus, Bacillus subtilis, Pseudomonas aeruginosa, and Escherichia coli, and Candida albicans. Different letters $(\mathrm{a}, \mathrm{b}, \mathrm{c}$, and $\mathrm{d})$ on bars at the same concertation refer that the mean values are significantly different $(p \leq 0.05)(n=3)$.

\subsection{Biotreatment of Tanning Effluent}

The main challenge facing different countries is discovering new active compounds that can be utilized in the treatment of different industrial effluents especially the countries that suffer from water scarcity. Nanotechnology especially that defined as green nanotechnology provides a new approach for producing new active compounds characterized as eco-friendly, with a large surface area, high stability, cost-effectiveness, and hence can be utilized to adsorb different contaminants [74,75]. Among highly contaminated industrial effluent is tanning wastewater, which appears a greenish-blue color because of the presence of chrome ions and other materials at high concentrations [76]. Therefore, the discharge of tanning effluent directly in the surrounding environment without treatment hinders sunlight penetration and hence decreases the pollutant oxidation process [77]. In the current study, the potential of different concentrations $\left(0.25,0.5,0.75\right.$, and $\left.1.0 \mu \mathrm{g} \mathrm{mL}^{-1}\right)$ of biogenically synthesized $\mathrm{MgO}-\mathrm{NPs}$ for treatment of tanning effluent at different interval times (30, $60,90,120,150,180$, and $240 \mathrm{~min}$ ) was investigated. Data recorded in Table 1 showed that the efficiency of biogenic MgO-NPs to decolorize the tanning effluent was concentration and time-dependent, meaning the decolorization percentages were increased as concentrations and contact time increased. This phenomenon can be attributed to the increase in adsorption sites by increasing the concentration of adsorbents [78]. At the lowest $\mathrm{MgO}-\mathrm{NP}$ concentration $\left(0.25 \mu \mathrm{g} \mathrm{mL}^{-1}\right)$, the decolorization percentages ranged from $16.1 \pm 1.6 \%$ after 30 min contact time to $46.6 \pm 3.2 \%$ after $240 \mathrm{~min}$ as compared to the control $(5.8 \pm 0.4 \%$ after 240 $\mathrm{min})$. At the highest concentration $\left(1.0 \mu \mathrm{g} \mathrm{mL} \mathrm{m}^{-1}\right)$, the adsorption sites increased and hence the decolorization increased to reach $89.1 \pm 1.6 \%$ after $120 \mathrm{~min}$. At this high concentration, the decolorization percentages were not significant at times 150, 180, and 240, i.e., $96.8 \pm 1.7 \%$, $97.5 \pm 1.6 \%$, and $97.7 \pm 1.7 \%$ (Table 1, Figure 9 ). The time and concentration are considered the main factors that should be taken into consideration on a large or industrial scale; therefore, $1.0 \mu \mathrm{g} \mathrm{mL}^{-1}$ of $\mathrm{MgO}-\mathrm{NPs}$ and $150 \mathrm{~min}$ were chosen as the optimal conditions for 
decolorization of tanning wastewater and to study the physicochemical parameters that indicate successful treatment.

Table 1. Decolorization percentages (\%) of tanning effluent using different concentrations $\left(0.25,0.5,0.75\right.$, and $\left.1.0 \mu \mathrm{g} \mathrm{mL}{ }^{-1}\right)$ of myco-synthesized MgO-NPs at different contact times $(30,60,90,120,150,180$, and $240 \mathrm{~min})$.

\begin{tabular}{|c|c|c|c|c|c|c|c|}
\hline \multirow{2}{*}{ MgO-NPs Concentration } & \multicolumn{7}{|c|}{ Decolorization Percentages (\%) after the Time (min) } \\
\hline & $30 \mathrm{~min}$ & $60 \mathrm{~min}$ & $90 \mathrm{~min}$ & $120 \mathrm{~min}$ & $150 \mathrm{~min}$ & $180 \mathrm{~min}$ & $240 \mathrm{~min}$ \\
\hline Control & $1.9 \pm 0.2$ & $2.2 \pm 0.2$ & $3.1 \pm 0.3$ & $3.8 \pm 0.4$ & $4.5 \pm 0.3$ & $5.2 \pm 0.3$ & $5.8 \pm 0.4$ \\
\hline $0.25 \mu \mathrm{g} \mathrm{mL}^{-1}$ & $16.1 \pm 1.6$ & $18.4 \pm 1.7$ & $21.3 \pm 2.1$ & $26.5 \pm 2.2$ & $31.3 \pm 2.2$ & $38.5 \pm 2.05$ & $46.6 \pm 3.2$ \\
\hline $0.5 \mu \mathrm{g} \mathrm{mL} L^{-1}$ & $28.5 \pm 2.7$ & $38.3 \pm 2.2$ & $45.7 \pm 3.1$ & $50.7 \pm 3.7$ & $54.8 \pm 2.01$ & $59.4 \pm 2.5$ & $61.6 \pm 1.8$ \\
\hline $0.75 \mu \mathrm{g} \mathrm{mL}^{-1}$ & $37.8 \pm 2.2$ & $49.3 \pm 3.3$ & $58.9 \pm 2.6$ & $69.7 \pm 1.9$ & $78.4 \pm 1.7$ & $81.4 \pm 0.3$ & $82.2 \pm 1.7$ \\
\hline $1.0 \mu \mathrm{g} \mathrm{mL}^{-1}$ & $53.5 \pm 3.6$ & $67.4 \pm 1.9$ & $77.8 \pm 1.3$ & $89.1 \pm 1.6$ & $96.8 \pm 1.7$ & $97.5 \pm 1.6$ & $97.7 \pm 1.7$ \\
\hline
\end{tabular}

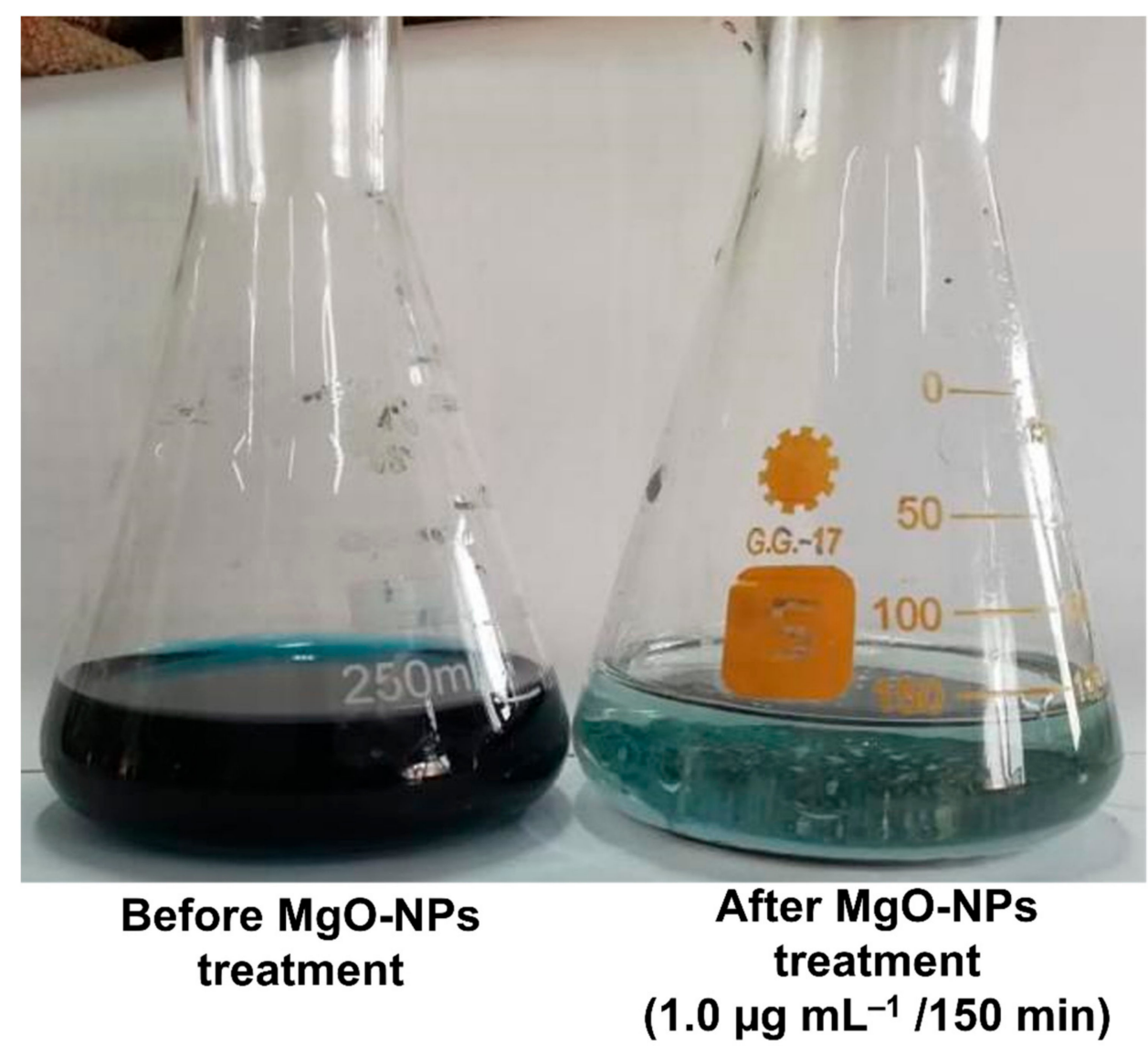

Figure 9. The decolorization of tanning effluent using biogenically synthesized MgO-NPs by A. terreus strain S1.

The successful treatment process by MgO-NPs is monitored by measuring the main factors including $\mathrm{pH}, \mathrm{BOD}, \mathrm{COD}$, TDS, TSS, and conductivity. These factors are high in tanning effluent due to hazardous chemicals, bicarbonates, calcium phosphates, chlorides, sulfates, nitrates, potassium, sodium, and various dissolved salts [79]. Moreover, the values of these factors are wide-ranging according to the chemicals used, tannery size, type of products, and water used [80]. The alkalinity of crude tanning wastewater is because of high amounts of carbonates and bicarbonates used during tanning steps [81]. Moreover, the high conductivity values of crude wastewater are because of the high content of salts and acids such as sodium and chrome salts. Further, high values of other factors such as TDS, TSS, and conductivity have adverse impacts on plants and aquatic eco-systems [6]. Data recorded in Table 2 showed a high level of measured factors in un-treated tanning 
effluents as follows: $\mathrm{pH}(10.5)$, TSS $\left(8776.3 \pm 5.8 \mathrm{mg} \mathrm{L}^{-1}\right)$, TDS $\left(15,720 \pm 4.1 \mathrm{mg} \mathrm{L}^{-1}\right), \mathrm{BOD}$ $\left(2345.7 \pm 7.0 \mathrm{mg} \mathrm{L}^{-1}\right), \operatorname{COD}\left(641.7 \pm 4.7 \mathrm{mg} \mathrm{L}^{-1}\right)$, and conductivity $\left(26,750.7 \pm 6.0 \mathrm{~S} \mathrm{~m}^{-1}\right)$. MgO-NPs exhibited high efficacy to decrease the factors of tanning effluent as follows: $\mathrm{pH}$ (8), TSS (172.0 $\left.\pm 4.8 \mathrm{mg} \mathrm{L}^{-1}\right)$, TDS $\left(252.0 \pm 4.1 \mathrm{mg} \mathrm{L}^{-1}\right)$, BOD $\left(255.0 \pm 5.1 \mathrm{mg} \mathrm{L}^{-1}\right)$, COD $\left(18.0 \pm 1.9 \mathrm{mg} \mathrm{L}^{-1}\right)$, and conductivity $\left(628.0 \pm 3.8 \mathrm{~S} \mathrm{~m}^{-1}\right)$. As shown, the MgO-NPs can remove BOD, COD, TSS, TDS, and conductivity with percentages of $89.1 \%, 97.2 \%, 98.04 \%$, $98.3 \%$, and $97.7 \%$.

Table 2. Physicochemical characterization and chromium ion adsorption from tanning effluent by MgO-NPs.

\begin{tabular}{cccc}
\hline $\begin{array}{c}\text { Physicochemical } \\
\text { Parameters }\end{array}$ & Control & $\begin{array}{c}\text { After MgO-NPs } \\
\text { Treatment }\end{array}$ & $\begin{array}{c}\text { Removal } \\
\text { Percentages (\%) }\end{array}$ \\
\hline $\mathrm{pH}$ & 10.5 & 8 & - \\
TSS $\left(\mathrm{mg} \mathrm{L}^{-1}\right)$ & $8776.3 \pm 5.8^{\mathrm{a}}$ & $172.0 \pm 4.8^{\mathrm{b}}$ & 98.04 \\
TDS $\left(\mathrm{mg} \mathrm{L}^{-1}\right)$ & $15,720 \pm 4.1^{\mathrm{a}}$ & $252.0 \pm 4.1^{\mathrm{b}}$ & 98.3 \\
BOD $\left(\mathrm{mg} \mathrm{L}^{-1}\right)$ & $2345.7 \pm 7.0^{\mathrm{a}}$ & $255.0 \pm 5.1^{\mathrm{b}}$ & 89.1 \\
COD $\left(\mathrm{mg} \mathrm{L}^{-1}\right)$ & $641.7 \pm 4.7^{\mathrm{a}}$ & $18.0 \pm 1.9^{\mathrm{b}}$ & 97.2 \\
${\text { Conductivity }\left(\mathrm{S} \mathrm{m}^{-1}\right)}_{\text {Cr mg L }}^{-1}$ & $26,750.7 \pm 6.0^{\mathrm{a}}$ & $628.0 \pm 3.8^{\mathrm{b}}$ & 97.7 \\
Different letters in the same row are significantly different $(p \leq 0.05)$ based on the Tukey LSD test. Data are
\end{tabular}
presented as the mean $\pm \mathrm{SD}(n=3)$.

\subsection{Chromium Ion Removal}

Chromium is the main heavy metal released into the environment from different industries such as textiles, electroplating, mining, and fertilizer manufacturing. Leather tanning is considering the main source for discharge of chromium [82]. The toxicity of chromium ions can be attributed to their mutagenic and carcinogenic properties, causing cancer of the lung and digestive tract, nausea, vomiting, diarrhea, epigastric pain, and hemorrhaging [83]. Therefore, there is an urgent need to discover new, high efficacy and eco-friendly adsorption compounds to remove heavy metals. MgO-NPs are characterized by cost-effectiveness, nontoxicity, high adsorption efficacy, abundance, eco-friendly, and biocompatibility [13]. Data represented in Table 2 showed the high efficacy of biogenically synthesized MgO-NPs to decrease the chromium ion concentration from $835.3 \pm 2.5 \mathrm{mg} \mathrm{L}^{-1}$ to $21.0 \pm 0.7 \mathrm{mg} \mathrm{L}^{-1}$ with a removal percentage of $97.5 \%$. The removal mechanism of heavy metals by MgO-NPs is dependent on precipitation and adsorption, whereas other nanomaterials such as nanotubes, $\mathrm{NiO}, \mathrm{ZrO}_{2}$, and $\mathrm{TiO}_{2}$ are dependent on adsorption only [84]. The adsorption process for these nanomaterials is controlled by the size, shape, surface, and textural properties [85]. On the other hand, the dissociation of $\mathrm{OH}^{-}$from the pre-synthesized $\mathrm{Mg}(\mathrm{OH})_{2}$ and the synergistic effects between precipitation and adsorption can be a reason for high MgO-NP adsorption [86]. Another mechanism to explain $\mathrm{Cr}$ removal is electrostatic attraction/repulsion [87]. The main $\mathrm{Cr}$ form that exists in an aquatic medium at $\mathrm{pH}>6.0$ is $\mathrm{CrO}_{4}{ }^{2-}$ [88]. The electrostatic attraction was achieved between the positive charge of NPs and the negative charge on the surface of chromate [89]. In our recent study, MgO-NPs synthesized by harnessing metabolites of Aspergillus niger F1 and Rhizopus oryzae E3 showed removal of $\mathrm{Cr}$ from tanning wastewater with percentages of $94.2 \pm 1.2 \%$ and $95.6 \pm 1.6$, respectively $[41,76]$. Therefore, this study provides a new, highly active nanomaterial that has the potential to adsorb various contaminants including heavy metals from tanning effluent and has antimicrobial activity.

\section{Materials and Methods}

\subsection{Reagents and Materials}

Chemicals used in the current study including magnesium nitrate hexahydrate $(\mathrm{Mg}$ $\left.\left(\mathrm{NO}_{3}\right)_{2} \cdot 6 \mathrm{H}_{2} \mathrm{O}\right)$ and sodium hydroxide $(\mathrm{NaOH})$ are analytical grade and were obtained from Sigma Aldrich, Cairo, Egypt. Malt Extract agar (MEA) media for fungal isolations 
and Muller Hinton agar media for antimicrobial activity were readymade (Oxoid, Thermo Fisher Scientific Inc. USA). The tannery wastewater was collected from Robbiki Leather City, 10th of Ramadan, Cairo, Egypt (GPS: N: $30^{\circ} 17^{\prime} 898^{\prime \prime}$, E: $\left.31^{\circ} 76^{\prime} 840^{\prime \prime}\right)$.

\subsection{Isolation and Identification of the Fungal Strain}

The fungal strain S1 used in the current study for the biosynthesis of MgO-NPs was isolated from a soil sample collected from El-Sharqia Governorate, Egypt (GPS: N: $\left.30^{\circ} 41^{\prime} 588.38^{\prime \prime}, \mathrm{E}: 31^{\circ} 56^{\prime} 211.84^{\prime \prime}\right)$. The isolation procedures were achieved according to Hashem, et al. [90] as follows: $100 \mu \mathrm{L}$ of the fifth dilution of a diluted soil sample was inoculated onto MEA plates and incubated for 3-4 days at $28 \pm 2{ }^{\circ} \mathrm{C}$. All different shapes and colors of fungal colonies were picked and re-inoculated again onto new MEA plates for purification. Finally, the purified colony was preserved on an MEA slant for further work.

The identification was accomplished by routine work including morphological and microscopic characterization. The primary identification was confirmed using internal transcribed spacer (ITS) sequence analysis. The ITS rDNA region was amplified using primers for ITS1 $\mathrm{f}$ (5-CTTGGTCATTTAGAGGAAGTAA-3) and ITS4 (5-TCCTCCGCTTATTGATATGC3) [91]. The PCR mixture contained $1 X$ PCR buffer, $0.5 \mathrm{mM} \mathrm{MgCl}_{2}$, $2.5 \mathrm{U}$ Taq DNA polymerase (QIAGEN, Germantown, MD 20874, USA), $0.25 \mathrm{mM}$ dNTP, $0.5 \mu \mathrm{L}$ of each primer, and $1 \mu \mathrm{g}$ of extracted genomic DNA. The PCR was performed in a DNA Engine Thermal Cycler (PTC-200, BIO-RAD, USA) with a program of $94^{\circ} \mathrm{C}$ for $3 \mathrm{~min}$, followed by 30 cycles of $94{ }^{\circ} \mathrm{C}$ for $30 \mathrm{~s}, 55^{\circ} \mathrm{C}$ for $30 \mathrm{~s}$, and $72{ }^{\circ} \mathrm{C}$ for $1 \mathrm{~min}$, followed by a final extension performed at $72{ }^{\circ} \mathrm{C}$ for $10 \mathrm{~min}$. The PCR product was checked for the expected sizes on $1 \%$ agarose gel and was sequenced by Sigma Company for scientific research, Egypt, with the two primers. The sequence was compared against the GenBank database using the NCBI BLAST tool. Multiple sequence alignment was done using the Clustal Omega software package (https:/ / www.ebi.ac.uk/Tools / msa / clustalo (accessed on 28 June 2021)), and a phylogenetic tree was constructed using the neighbor-joining method with MEGA (Version 6.1) software, with confidence tested by bootstrap analysis (1000 repeats).

\subsection{Biogenic Synthesis of $\mathrm{MgO}-\mathrm{NPS}$}

The fungal biomass filtrate utilized as a biocatalyst for the biogenic synthesis of $\mathrm{MgO}-$ NPs was prepared through the inoculation of three disks $(0.8 \mathrm{~cm}$ in diameter) of fungal strain $\mathrm{S} 1$ into $100 \mathrm{~mL}$ of malt extract broth (MAB) medium and incubated for five days at $28 \pm 2{ }^{\circ} \mathrm{C}$ under shaking conditions (150 rpm). At the end of the incubation period, the inoculated MAB medium was centrifuged to collect the fungal biomass. The collected fungal biomass $(10 \mathrm{~g})$ was resuspended in $100 \mathrm{~mL}$ distilled water for $48 \mathrm{~h}$. at $28 \pm 2{ }^{\circ} \mathrm{C}$ under shaking conditions. The previous mixture was centrifuged at $15,000 \mathrm{rpm}$ for three minutes; the upper layer (supernatant) was collected and used for biosynthesis of MgO-NPs as follows.

$\mathrm{Mg}\left(\mathrm{NO}_{3}\right)_{2} \cdot 6 \mathrm{H}_{2} \mathrm{O}(76.6 \mathrm{mg})$ was dissolved in $10 \mathrm{~mL}$ dis. $\mathrm{H}_{2} \mathrm{O}$ and the volume made to $100 \mathrm{~mL}$ by adding $90 \mathrm{~mL}$ fungal biomass filtrate to a final concentration of $3 \mathrm{mM}$. The previous mixture was incubated for $24 \mathrm{~h}$ at room temperature. At first, $\mathrm{Mg}(\mathrm{OH})_{2}$ appeared as a turbid white precipitate that was collected and washed with dis. $\mathrm{H}_{2} \mathrm{O}$ before drying at $100{ }^{\circ} \mathrm{C}$ for one hour (Equation (1)). After that, $\mathrm{Mg}(\mathrm{OH})_{2}$ was subjected to calcination at $400{ }^{\circ} \mathrm{C}$ for $3 \mathrm{~h}$ to form MgO-NPs (Equation (2)) [92].

$$
\begin{gathered}
\mathrm{Mg}\left(\mathrm{NO}_{3}\right)_{2} \cdot 6 \mathrm{H}_{2} \mathrm{O}+\mathrm{H}_{2} \mathrm{O} \underset{\text { Metabolites }}{\stackrel{\text { Fungal }}{\rightarrow}} \mathrm{Mg}(\mathrm{OH})_{2} \\
\mathrm{Mg}(\mathrm{OH})_{2} \stackrel{400^{\circ} \mathrm{C}}{\rightarrow} \mathrm{MgO}
\end{gathered}
$$

Optimization factors of MgO-NPs biosynthesis.

The physical and chemical factors affecting the production as well as the distribution of MgO-NPs were optimized. Different factors such as temperature, contact times, 
different $\mathrm{pH}$ values, and $\mathrm{Mg}\left(\mathrm{NO}_{3}\right)_{2} \cdot 6 \mathrm{H}_{2} \mathrm{O}$ concentrations are investigated by detecting the maximum surface plasmon resonance by a UV-Vis spectrophotometer (Jenway 6305, Staffordshire, UK). The different contact times $(6,12,24,36,48$, and $72 \mathrm{~min})$ between fungal biomass filtrate and $\mathrm{Mg}\left(\mathrm{NO}_{3}\right)_{2} \cdot 6 \mathrm{H}_{2} \mathrm{O}$ were assessed. Moreover, the incubation temperatures $\left(25^{\circ} \mathrm{C}, 30^{\circ} \mathrm{C}, 35^{\circ} \mathrm{C}\right.$, and $\left.40{ }^{\circ} \mathrm{C}\right)$, different $\mathrm{pH}$ values $(6,7,8,9,10$, and 11$)$, and different $\mathrm{Mg}\left(\mathrm{NO}_{3}\right)_{2} \cdot 6 \mathrm{H}_{2} \mathrm{O}$ concentrations (1-5 mM) were assessed. At the end of each experiment, $1.0 \mathrm{~mL}$ of the sample was withdrawn to measure the color intensity at maximum SPR at $\lambda_{\max }=280 \mathrm{~nm}$.

\subsection{Characterization of Biosynthesized $\mathrm{MgO}-\mathrm{NPs}$}

Fourier transform infrared (FT-IR) spectroscopy (Agilent system Cary 660 FT-IR model) was used to inspect the functional groups present in the fungal biomass filtrate and involved in the reduction and stabilization of MgO-NPs. The MgO-NP sample was mixed with $\mathrm{KBr}$ and scanned in the range of 400 to $4000 \mathrm{~cm}^{-1}$.

The physicochemical characterizations of biogenically synthesized MgO-NPs were accomplished using Transmission Electron Microscopy (TEM) (JEOL 1010, Japan, acceleration voltage of $200 \mathrm{KV}$ ) to detect the MgO-NP sizes and shapes. A few drops of MgO-NPs suspension were added to the carbon-copper grid, which was subjected to vacuum desiccation before placing on a TEM-holder for analysis [93]. The elemental analysis of biogenically synthesized MgO-NPs was measured using Scanning Electron Microscopy connected to energy dispersive X-rays (SEM-EDX) ((JEOL, JSM-6360LA, Japan). Moreover, the crystallographic structure of MgO-NPs was investigated using X-ray diffraction (XRD) analysis by an X'Pert pro diffractometer (Philips, Eindhoven, Netherlands). The XRD analysis condition was achieved at $2 \theta$ values of $4^{\circ}$ to $80^{\circ}$, Ni-filtered $\mathrm{Cu} \mathrm{Ka}$ as an X-ray radiation source, and the operating voltage and current were $40 \mathrm{KV}$ and $30 \mathrm{~mA}$, respectively. Based on XRD analysis, the average size of MgO-NPs was measured using the Debye-Scherrer equation [94] as follows:

$$
\mathrm{D}=0.9 \lambda / \beta \operatorname{Cos} \theta
$$

where $\mathrm{D}$ is the average particle size; 0.9 is the Scherrer's' constant; $\lambda$ is the wavelength of $X$-ray radiation $(0.154 \mathrm{~nm}) ; \beta$ and $\theta$ are the half of maximum intensity and Bragg's angle, respectively.

The size distribution of biogenic MgO-NPs in colloidal solution was detected by dynamic light scattering (DLS) analysis. The sample was subjected to measurement by Zeta sizer nano series (Nano ZS), Malvern, UK.

\subsection{Antimicrobial Activity}

The efficacy of biogenic MgO-NPs to inhibit the growth of pathogenic Gram-positive bacteria (Bacillus subtilis ATCC 6633 and Staphylococcus aureus ATCC 6538), Gram-negative bacteria (Pseudomonas aeruginosa ATCC 9022 and Escherichia coli ATCC 8739), and unicellular fungi represented by Candida albicans ATCC 10231 was investigated using the agar well-diffusion method. Under aseptic conditions, each bacterial strain was inoculated into Mueller-Hinton agar medium (Oxid, ready-prepared), whereas the unicellular fungi were inoculated into yeast extract peptone dextrose (YEPD) agar medium (containing $g$ $\mathrm{L}^{-1}$ :glucose, 20; peptone, 20; yeast extract, 10; agar, 20; distilled water, $1000 \mathrm{~mL}$ ). Three wells $(0.7 \mathrm{~cm}$ diameter) were prepared in the inoculated plates and filled with $100 \mu \mathrm{L}$ of biosynthesized MgO-NPs $\left(200 \mu \mathrm{g} \mathrm{mL}^{-1}\right)$. Different concentrations of MgO-NPs (150, 100,50 , and $25 \mu \mathrm{g} \mathrm{mL}^{-1}$ ) were prepared to detect the minimum inhibitory concentrations (MIC). The plates were kept in the refrigerator for $1.0 \mathrm{~h}$ before incubation at $35 \pm 2{ }^{\circ} \mathrm{C}$ for $24 \mathrm{~h}$. At the end of the incubation period, the diameters of the inhibition zone (ZOI) that appeared around each well were measured in $\mathrm{mm}$ [76]. The experiment was carried out in triplicate. 


\subsection{Tanning Effluent Treatment and Bio-Adsorption of Chromium Ions}

The potential of MgO-NPs to decolorize the tanning effluent was investigated. Briefly, the tanning effluent was mixed with MgO-NPs $\left(0.25,0.5,0.75\right.$, and $\left.1.0 \mu \mathrm{gL}^{-1}\right)$ for different contact times $(30,60,90,120,150,180$, and $240 \mathrm{~min})$ in a $250 \mathrm{~mL}$ conical flask under shaking conditions (150 rpm). Each treatment was performed in triplicate. The formed mixture was stirred for $30 \mathrm{~min}$ before the experiment reached absorption/desorption equilibrium. The decolorization ratio was measured at the end of each different contact time as follows.

Approximately $1.0 \mathrm{~mL}$ of the mixture (tanning effluent with MgO-NPs) was withdrawn, centrifuged at $5000 \mathrm{rpm}$ for $8 \mathrm{~min}$, and used to detect the optical density of the treated tanning effluent at the maximum $\lambda_{\max }=550 \mathrm{~nm}$ by a spectrophotometer $(721 \mathrm{spec}-$ trophotometers, M-ETCAL). The decolorization ratio (\%) of the tanning effluent was measured using the following equation [48].

$$
\mathrm{D}(\%)=\frac{\mathrm{C}_{0}-\mathrm{C}_{\mathrm{t}}}{\mathrm{C}_{0}} \times 100
$$

where, $D$ is the decolorization ratio $\% ; C_{0}$ is the absorbance at zero time; $C_{t}$ is the absorbance after specific time $t(\mathrm{~min})$.

At the optimum contact time and suitable $\mathrm{MgO}-\mathrm{NP}$ concentration, the chemical parameters including biological oxygen demand (BOD), chemical oxygen demand (COD), total dissolved solids (TDS), total suspended solids (TSS), and conductivity were calculated according to the standard recommended methods [95].

Chromium ( $\mathrm{Cr}$ ) ion was the main common heavy metal present in the tanning effluent. Therefore, the $\mathrm{Cr}$ ion concentration before and after treatment with optimum MgO-NP concentration and optimum contact time was measured using atomic adsorption spectroscopy (A PerkinElmer Analyst 800 atomic spectrometer).

\subsection{Statistical Analysis}

The means of three replications and standard error $( \pm \mathrm{SE})$ were calculated for all the results obtained. Data were subjected to statistical analysis by the statistical package SPSS $v 17$. The mean difference comparison between the treatments was analyzed by $t$-tests or analysis of variance (ANOVA) and subsequently by Tukey's HSD test at $p<0.05$.

\section{Conclusions}

In the current study, $\mathrm{MgO}-\mathrm{NPs}$ were fabricated through the reduction of $\mathrm{Mg}\left(\mathrm{NO}_{3}\right)_{2}$. $6 \mathrm{H}_{2} \mathrm{O}$ by metabolites secreted by $A$. terreus strain $\mathrm{S1}$. The first indicator for successful MgO$\mathrm{NP}$ synthesis was a color change from colorless to turbid white and detection of maximum surface plasmon resonance at $280 \mathrm{~nm}$. The various parameters such as metal precursor concentration, contact time, temperature, and $\mathrm{pH}$ values that affect the production process were optimized. The physicochemical characterization was achieved by TEM, SEM-EDX, XRD, DLS, and FT-IR spectroscopy. The role of fungal metabolites in the reduction, capping, and the stabilizing process was detected by FT-IR. Moreover, the MgO-NP size ( 8.0 to $38.0 \mathrm{~nm}$ ), crystallographic structure, qualitative and quantitative compositions, and dispersion of NPs in colloid solution were confirmed by TEM, XRD, SEM-EDX, and DLS analyses, respectively. The antimicrobial activity of biosynthesized MgO-NPs was assessed against pathogenic S. aureus, B. subtilis, P. aeruginosa, E. coli, and C. albicans. Data showed that the inhibitory action of MgO-NPs was concentration-dependent. Further, the MIC value was detected as $50 \mu \mathrm{g} \mathrm{mL}^{-1}$ for P. aeruginosa with ZOI of $8.3 \pm 0.3 \mathrm{~mm}$, whereas E. coli, C. albicans, S. aureus, and B. subtilis had an MIC value $100 \mu \mathrm{g} \mathrm{mL} \mathrm{m}^{-1}$ with ZOIs of $8.0 \pm 0.0,8.7 \pm 0.9,8.0 \pm 0.0$, and $9.3 \pm 0.6 \mathrm{~mm}$, respectively. Moreover, biogenically synthesized MgO-NPs exhibited the ability to decolorize the greenish-blue color of tanning effluent with a percentage of $96.8 \pm 1.7 \%$ after $150 \mathrm{~min}$. At these decolorization percentages, the physicochemical parameters of tanning effluent including TSS, TDS, BOD, COD, and conductivity were highly reduced. Finally, the MgO-NPs showed high removal of 
chromium ions with a percentage of $97.5 \%$. This study provides a promising eco-friendly, cost-effective, and biocompatible nanomaterial for various applications.

Author Contributions: Conceptualization, S.E.-D.H. and A.F.; methodology, E.S.; A.M.E.; S.E.-D.H.; S.S.S.; A.A.R.; M.H.; A.F.; software, E.S.; S.E.-D.H.; A.F.; validation, E.S.; A.M.E.; S.E.-D.H.; S.S.S.; A.A.R.; A.F.; formal analysis, E.S.; A.M.E.; S.E.-D.H.; S.S.S.; A.A.R.; M.H.; A.F.; investigation, E.S.; A.M.E.; S.E.-D.H.; S.S.S.; A.A.R.; M.H.; A.F.; resources, E.S.; A.M.E.; S.E.-D.H.; S.S.S.; A.A.R.; A.F. data curation, E.S.; A.M.E.; S.E.-D.H.; S.S.S.; A.A.R.; M.H.; A.F. writing-original draft preparation, E.S.; A.M.E.; A.A.R.; A.F. writing—review and editing, E.S.; A.M.E.; S.E.-D.H.; S.S.S.; A.A.R.; M.H.; A.F.; H.A.S.; E.M.S.; F.M.S. visualization, E.S.; A.M.E.; S.E.-D.H.; A.F.; supervision, E.S., S.E.-D.H.; A.F.; project administration, E.S., S.E.-D.H.; A.F.; funding acquisition, F.M.S., E.M.S. and H.A.S. All authors have read and agreed to the published version of the manuscript.

Funding: This research received no external funding.

Data Availability Statement: The data presented in this study are available on request from the corresponding author.

Acknowledgments: We appreciate and thank Taif University for the financial support for Taif University Researchers Supporting Project (TURSP-2020/07), Taif University, Taif, Saudi Arabia.

Conflicts of Interest: The authors declare no conflict of interest.

\section{References}

1. Song, M.; Wang, R.; Zeng, X. Water resources utilization efficiency and influence factors under environmental restrictions. J. Clean. Prod. 2018, 184, 611-621. [CrossRef]

2. Jobby, R.; Jha, P.; Yadav, A.K.; Desai, N. Biosorption and biotransformation of hexavalent chromium [Cr(VI)]: A comprehensive review. Chemosphere 2018, 207, 255-266. [CrossRef] [PubMed]

3. Selim, M.T.; Salem, S.S.; Mohamed, A.A.; El-Gamal, M.S.; Awad, M.F.; Fouda, A. Biological Treatment of Real Textile Effluent Using Aspergillus flavus and Fusarium oxysporium and Their Consortium along with the Evaluation of Their Phytotoxicity. J. Fungi 2021, 7, 193. [CrossRef] [PubMed]

4. Hamza, M.F.; Hamad, N.A.; Hamad, D.M.; Khalafalla, M.S.; Abdel-Rahman, A.A.; Zeid, I.F.; Wei, Y.; Hessien, M.M.; Fouda, A.; Salem, W.M. Synthesis of Eco-Friendly Biopolymer, Alginate-Chitosan Composite to Adsorb the Heavy Metals, Cd(II) and Pb(II) from Contaminated Effluents. Materials 2021, 14, 2189. [CrossRef]

5. Salem, S.S.; Mohamed, A.; El-Gamal, M.; Talat, M.; Fouda, A. Biological Decolorization and Degradation of Azo Dyes from Textile Wastewater Effluent by Aspergillus niger. Egypt. J. Chem. 2019, 62, 1799-1813.

6. Ali, A.; Shaikh, I.A.; Abbasi, N.A.; Firdous, N.; Ashraf, M.N. Enhancing water efficiency and wastewater treatment using sustainable technologies: A laboratory and pilot study for adhesive and leather chemicals production. J. Water Process Eng. 2020, 36, 101308. [CrossRef]

7. Wang, D.; He, S.; Shan, C.; Ye, Y.; Ma, H.; Zhang, X.; Zhang, W.; Pan, B. Chromium speciation in tannery effluent after alkaline precipitation: Isolation and characterization. J. Hazard. Mater. 2016, 316, 169-177. [CrossRef]

8. Bhattacharya, A.; Gupta, A. Evaluation of Acinetobacter sp. B9 for Cr (VI) resistance and detoxification with potential application in bioremediation of heavy-metals-rich industrial wastewater. Environ. Sci. Pollut. Res. Int. 2013, 20, 6628-6637. [CrossRef]

9. Soliman, A.M.; Abdel-Latif, W.; Shehata, I.H.; Fouda, A.; Abdo, A.M.; Ahmed, Y.M. Green Approach to Overcome the Resistance Pattern of Candida spp. Using Biosynthesized Silver Nanoparticles Fabricated by Penicillium chrysogenum F9. Biol. Trace Elem. Res. 2021, 199, 800-811. [CrossRef]

10. Hamza, M.F.; Fouda, A.; Elwakeel, K.Z.; Wei, Y.; Guibal, E.; Hamad, N.A. Phosphorylation of Guar Gum/Magnetite/Chitosan Nanocomposites for Uranium (VI) Sorption and Antibacterial Applications. Molecules 2021, 26, 1920. [CrossRef]

11. Salem, S.; Fouda, A. Green Synthesis of Metallic Nanoparticles and Their Prospective Biotechnological Applications: An Overview. Biol. Trace Elem. Res. 2020, 199, 344-370. [CrossRef]

12. Badawy, A.A.; Abdelfattah, N.A.H.; Salem, S.S.; Awad, M.F.; Fouda, A. Efficacy Assessment of Biosynthesized Copper Oxide Nanoparticles (CuO-NPs) on Stored Grain Insects and Their Impacts on Morphological and Physiological Traits of Wheat (Triticum aestivum L.) Plant. Biology 2021, 10, 233. [CrossRef]

13. Abinaya, S.; Kavitha, H.P.; Prakash, M.; Muthukrishnaraj, A. Green synthesis of magnesium oxide nanoparticles and its applications: A review. Sustain. Chem. Pharm. 2021, 19, 100368. [CrossRef]

14. Vergheese, M.; Vishal, S.K. Green synthesis of magnesium oxide nanoparticles using Trigonella foenum-graecum leaf extract and its antibacterial activity. J. Pharm. Phytochem. 2018, 7, 1193-1200.

15. Abdulkhaleq, N.A.; Nayef, U.M.; Albarazanchi, A.K.H. MgO nanoparticles synthesis via laser ablation stationed on porous silicon for photoconversion application. Optik 2020, 212, 164793. [CrossRef]

16. Sofi, A.H.; Akhoon, S.A.; Mir, J.F.; Rather, M.U.D. Magnesium Oxide (MgO): A Viable Agent for Antimicrobial Activity. In Applications of Nanomaterials in Agriculture, Food Science, and Medicine; IGI Global: Hershey, PA, USA, $2021 ;$ pp. 98-105. 
17. Fouda, A.; Awad, M.A.; Eid, A.M.; Saied, E.; Barghoth, M.G.; Hamza, M.F.; Awad, M.F.; Abdelbary, S.; Hassan, S.E. An EcoFriendly Approach to the Control of Pathogenic Microbes and Anopheles stephensi Malarial Vector Using Magnesium Oxide Nanoparticles (Mg-NPs) Fabricated by Penicillium chrysogenum. Int. J. Mol. Sci. 2021, 22, 5096. [CrossRef]

18. Refat, M.S.; Ibrahim, H.K.; Sowellim, S.Z.A.; Soliman, M.H.; Saeed, E.M. Spectroscopic and Thermal Studies of Mn(II), Fe(III), $\mathrm{Cr}$ (III) and Zn(II) Complexes Derived from the Ligand Resulted by the Reaction Between 4-Acetyl Pyridine and Thiosemicarbazide. J. Inorg. Organomet. Polym. 2009, 19, 521. [CrossRef]

19. Jagadeeshan, S.; Parsanathan, R. Nano-metal oxides for antibacterial activity. In Advanced Nanostructured Materials for Environmental Remediation; Springer: Cham, Switzerland, 2019; pp. 59-90.

20. Srivastava, V.; Sharma, Y.C.; Sillanpää, M. Green synthesis of magnesium oxide nanoflower and its application for the removal of divalent metallic species from synthetic wastewater. Ceram. Int. 2015, 41, 6702-6709. [CrossRef]

21. Parham, S.; Wicaksono, D.H.B.; Bagherbaigi, S.; Lee, S.L.; Nur, H. Antimicrobial Treatment of Different Metal Oxide Nanoparticles: A Critical Review. J. Chin. Chem. Soc. 2016, 63, 385-393. [CrossRef]

22. Saravanathamizhan, R.; Perarasu, V.T. Chapter 6-Improvement of Biodegradability Index of Industrial Wastewater Using Different Pretreatment Techniques. In Wastewater Treatment; Shah, M.P., Sarkar, A., Mandal, S., Eds.; Elsevier: Amsterdam, The Netherlands, 2021; pp. 103-136.

23. Rani, P.; Kaur, G.; Rao, K.V.; Singh, J.; Rawat, M. Impact of Green Synthesized Metal Oxide Nanoparticles on Seed Germination and Seedling Growth of Vigna radiata (Mung Bean) and Cajanus cajan (Red Gram). J. Inorg. Organomet. Polym. Mater. 2020, 30, 4053-4062. [CrossRef]

24. Eid, A.M.; Fouda, A.; Niedbała, G.; Hassan, S.E.-D.; Salem, S.S.; Abdo, A.M.; Hetta, H.F.; Shaheen, T.I. Endophytic Streptomyces laurentii Mediated Green Synthesis of Ag-NPs with Antibacterial and Anticancer Properties for Developing Functional Textile Fabric Properties. Antibiotics 2020, 9, 641. [CrossRef] [PubMed]

25. Samak, D.H.; El-Sayed, Y.S.; Shaheen, H.M.; El-Far, A.H.; Abd El-Hack, M.E.; Noreldin, A.E.; El-Naggar, K.; Abdelnour, S.A.; Saied, E.M.; El-Seedi, H.R.; et al. Developmental Toxicity of Carbon Nanoparticles during Embryogenesis in Chicken. Environ Sci Pollut Res 2020, 27, 19058-19072. [CrossRef] [PubMed]

26. McClenny, N. Laboratory detection and identification of Aspergillus species by microscopic observation and culture: The traditional approach. Med. Mycol. 2005, 43 (Suppl. 1), S125-S128. [CrossRef] [PubMed]

27. Diba, K.; Kordbacheh, P.; Mirhendi, S.; Rezaie, S.; Mahmoudi, M. Identification of Aspergillus species using morphological characteristics. Pak. J. Med Sci. 2007, 23, 867.

28. Risslegger, B.; Zoran, T.; Lackner, M.; Aigner, M.; Sánchez-Reus, F.; Rezusta, A.; Chowdhary, A.; Taj-Aldeen, S.J.; Arendrup, M.C.; Oliveri, S.; et al. A prospective international Aspergillus terreus survey: An EFISG, ISHAM and ECMM joint study. Clin. Microbiol. Infect. Off. Publ. Eur. Soc. Clin. Microbiol. Infect. Dis. 2017, 23, 776.e1-776.e5. [CrossRef]

29. Subhan, M.; Faryal, R.; Macreadie, I. Exploitation of Aspergillus terreus for the Production of Natural Statins. J. Fungi 2016, 2, 13. [CrossRef]

30. Sethi, B.K.; Nanda, P.K.; Sahoo, S. Characterization of biotechnologically relevant extracellular lipase produced by Aspergillus terreus NCFT 4269.10. Braz. J. Microbiol. 2016, 47, 143-149. [CrossRef]

31. Raliya, R.; Tarafdar, J.C. Biosynthesis and characterization of zinc, magnesium and titanium nanoparticles: An eco-friendly approach. Int. Nano Lett. 2014, 4, 93. [CrossRef]

32. Lashin, I.; Fouda, A.; Gobouri, A.A.; Azab, E.; Mohammedsaleh, Z.M.; Makharita, R.R. Antimicrobial and In Vitro Cytotoxic Efficacy of Biogenic Silver Nanoparticles (Ag-NPs) Fabricated by Callus Extract of Solanum incanum L. Biomolecules 2021, 11, 341. [CrossRef]

33. Grijseels, S.; Nielsen, J.C.; Nielsen, J.; Larsen, T.O.; Frisvad, J.C.; Nielsen, K.F.; Frandsen, R.J.N.; Workman, M. Physiological characterization of secondary metabolite producing Penicillium cell factories. Fungal Biol. Biotechnol. 2017, 4, 8. [CrossRef]

34. Shaheen, T.I.; Fouda, A.; Salem, S.S. Integration of Cotton Fabrics with Biosynthesized CuO Nanoparticles for Bactericidal Activity in the Terms of Their Cytotoxicity Assessment. Ind. Eng. Chem. Res. 2021, 60, 1553-1563. [CrossRef]

35. Hassan, S.E.-D.; Fouda, A.; Radwan, A.A.; Salem, S.S.; Barghoth, M.G.; Awad, M.A.; Abdo, A.M.; El-Gamal, M.S. Endophytic actinomycetes Streptomyces spp mediated biosynthesis of copper oxide nanoparticles as a promising tool for biotechnological applications. JBIC J. Biol. Inorg. Chem. 2019, 24, 377-393. [CrossRef]

36. Loo, Y.Y.; Rukayadi, Y.; Nor-Khaizura, M.-A.-R.; Kuan, C.H.; Chieng, B.W.; Nishibuchi, M.; Radu, S. In Vitro Antimicrobial Activity of Green Synthesized Silver Nanoparticles Against Selected Gram-negative Foodborne Pathogens. Front. Microbiol. 2018, 9, 1555. [CrossRef]

37. Nguyen, D.T.C.; Dang, H.H.; Vo, D.-V.N.; Bach, L.G.; Nguyen, T.D.; Tran, T.V. Biogenic synthesis of MgO nanoparticles from different extracts (flower, bark, leaf) of Tecoma stans (L.) and their utilization in selected organic dyes treatment. J. Hazard. Mater. 2021, 404, 124146. [CrossRef]

38. Ogunyemi, S.O.; Zhang, F.; Abdallah, Y.; Zhang, M.; Wang, Y.; Sun, G.; Qiu, W.; Li, B. Biosynthesis and characterization of magnesium oxide and manganese dioxide nanoparticles using Matricaria chamomilla L. extract and its inhibitory effect on Acidovorax oryzae strain RS-2. Artif. Cells Nanomed. Biotechnol. 2019, 47, 2230-2239. [CrossRef]

39. Hamida, R.S.; Ali, M.A.; Abdelmeguid, N.E.; Al-Zaban, M.I.; Baz, L.; Bin-Meferij, M.M. Lichens-A Potential Source for Nanoparticles Fabrication: A Review on Nanoparticles Biosynthesis and Their Prospective Applications. J. Fungi 2021, 7, 291. [CrossRef] 
40. Mohd Yusof, H.; Mohamad, R.; Zaidan, U.H.; Abdul Rahman, N.A. Microbial synthesis of zinc oxide nanoparticles and their potential application as an antimicrobial agent and a feed supplement in animal industry: A review. J. Anim. Sci. Biotechnol. 2019, 10, 57. [CrossRef]

41. Hassan, S.E.; Fouda, A.; Saied, E.; Farag, M.M.S.; Eid, A.M.; Barghoth, M.G.; Awad, M.A.; Hamza, M.F.; Awad, M.F. Rhizopus oryzaeMediated Green Synthesis of Magnesium Oxide Nanoparticles (MgO-NPs): A Promising Tool for Antimicrobial, Mosquitocidal Action, and Tanning Effluent Treatment. J. Fungi 2021, 7, 372. [CrossRef]

42. Muangban, J.; Jaroenapibal, P. Effects of precursor concentration on crystalline morphologies and particle sizes of electrospun $\mathrm{WO}_{3}$ nanofibers. Ceram. Int. 2014, 40, 6759-6764. [CrossRef]

43. Jeevanandam, J.; San Chan, Y.; Jing Wong, Y.; Siang Hii, Y. Biogenic synthesis of magnesium oxide nanoparticles using Aloe barbadensis leaf latex extract. IOP Conf. Ser. Mater. Sci. Eng. 2020, 943, 012030. [CrossRef]

44. Naseem, K.; Zia Ur Rehman, M.; Ahmad, A.; Dubal, D.; AlGarni, T.S. Plant Extract Induced Biogenic Preparation of Silver Nanoparticles and Their Potential as Catalyst for Degradation of Toxic Dyes. Coatings 2020, 10, 1235. [CrossRef]

45. Irfan, M.; Moniruzzaman, M.; Ahmad, T.; Samsudin, M.F.R.; Bashir, F.; Butt, M.T.; Ashraf, H. Identifying the role of process conditions for synthesis of stable gold nanoparticles and insight detail of reaction mechanism. Inorg. Nano Met. Chem. 2021, 1-14. [CrossRef]

46. Sahu, P.K.; Sahu, P.K.; Agarwal, D.D. Role of basicity and the catalytic activity of KOH loaded MgO and hydrotalcite as catalysts for the efficient synthesis of 1-[(2-benzothiazolylamino)arylmethyl]-2-naphthalenols. RSC Adv. 2015, 5, 69143-69151. [CrossRef]

47. Vijayanandan, A.S.; Balakrishnan, R.M. Biosynthesis of cobalt oxide nanoparticles using endophytic fungus Aspergillus nidulans. J. Environ. Manag. 2018, 218, 442-450. [CrossRef]

48. Fouda, A.; Hassan, S.E.-D.; Abdel-Rahman, M.A.; Farag, M.M.S.; Shehal-deen, A.; Mohamed, A.A.; Alsharif, S.M.; Saied, E.; Moghanim, S.A.; Azab, M.S. Catalytic degradation of wastewater from the textile and tannery industries by green synthesized hematite $\left(\alpha-\mathrm{Fe}_{2} \mathrm{O}_{3}\right)$ and magnesium oxide (MgO) nanoparticles. Curr. Res. Biotechnol. 2021, 3, 29-41. [CrossRef]

49. Ahmadi, M.; Ghasemi, M.R.; Rafsanjani, H.H. Study of different parameters in $\mathrm{TiO}_{2}$ nanoparticles formation. J. Mater. Sci. Eng. 2011, 5, 87 .

50. Fouda, A.; Abdel-Maksoud, G.; Saad, H.A.; Gobouri, A.A.; Mohammedsaleh, Z.M.; El-Sadany, M.A. The efficacy of silver nitrate $\left(\mathrm{AgNO}_{3}\right)$ as a coating agentto protect paper against high deteriorating microbes. Catalysts 2021, 11, 310. [CrossRef]

51. Amina, M.; Al Musayeib, N.M.; Alarfaj, N.A.; El-Tohamy, M.F.; Oraby, H.F.; Al Hamoud, G.A.; Bukhari, S.I.; Moubayed, N.M.S. Biogenic green synthesis of $\mathrm{MgO}$ nanoparticles using Saussurea costus biomasses for a comprehensive detection of their antimicrobial, cytotoxicity against MCF-7 breast cancer cells and photocatalysis potentials. PLoS ONE 2020, 15, e0237567. [CrossRef] [PubMed]

52. Asami, H.; Tokugawa, M.; Masaki, Y.; Ishiuchi, S.-i.; Gloaguen, E.; Seio, K.; Saigusa, H.; Fujii, M.; Sekine, M.; Mons, M. Effective Strategy for Conformer-Selective Detection of Short-Lived Excited State Species: Application to the IR Spectroscopy of the N1H Keto Tautomer of Guanine. J. Phys. Chem. A 2016, 120, 2179-2184. [CrossRef] [PubMed]

53. Dobrucka, R. Synthesis of MgO Nanoparticles Using Artemisia abrotanum Herba Extract and Their Antioxidant and Photocatalytic Properties. Iran. J. Sci. Technol. Trans. A Sci. 2018, 42, 547-555. [CrossRef]

54. Brotton, S.J.; Lucas, M.; Jensen, T.N.; Anderson, S.L.; Kaiser, R.I. Spectroscopic Study on the Intermediates and Reaction Rates in the Oxidation of Levitated Droplets of Energetic Ionic Liquids by Nitrogen Dioxide. J. Phys. Chem. A 2018, 122, $7351-7377$. [CrossRef]

55. Karimi, B.; Khorasani, M.; Vali, H.; Vargas, C.; Luque, R. Palladium Nanoparticles Supported in the Nanospaces of ImidazoliumBased Bifunctional PMOs: The Role of Plugs in Selectivity Changeover in Aerobic Oxidation of Alcohols. ACS Catal. 2015, 5, 4189-4200. [CrossRef]

56. Suresh, J.; Pradheesh, G.; Alexramani, V.; Sundrarajan, M.; Hong, S.I. Green synthesis and characterization of hexagonal shaped $\mathrm{MgO}$ nanoparticles using insulin plant (Costus pictus D. Don) leave extract and its antimicrobial as well as anticancer activity. Adv. Powder Technol. 2018, 29, 1685-1694. [CrossRef]

57. Umaralikhan, L.; Jamal Mohamed Jaffar, M. Green Synthesis of MgO Nanoparticles and it Antibacterial Activity. Iran. J. Sci. Technol. Trans. A Sci. 2018, 42, 477-485. [CrossRef]

58. Fouda, A.; Abdel-Maksoud, G.; Abdel-Rahman, M.A.; Eid, A.M.; Barghoth, M.G.; El-Sadany, M.A.-H. Monitoring the effect of biosynthesized nanoparticles against biodeterioration of cellulose-based materials by Aspergillus niger. Cellulose 2019, 26, 6583-6597. [CrossRef]

59. Aref, M.S.; Salem, S.S. Bio-callus synthesis of silver nanoparticles, characterization, and antibacterial activities via Cinnamomum camphora callus culture. Biocatal. Agric. Biotechnol. 2020, 27, 101689. [CrossRef]

60. Huang, L.; Li, D.; Lin, Y.; Evans, D.G.; Duan, X. Influence of nano-MgO particle size on bactericidal action againstBacillus subtilis var. niger. Chin. Sci. Bull. 2005, 50, 514-519. [CrossRef]

61. Jian, W.; Ma, Y.; Wu, H.; Zhu, X.; Wang, J.; Xiong, H.; Lin, L.; Wu, L. Fabrication of highly stable silver nanoparticles using polysaccharide-protein complexes from abalone viscera and antibacterial activity evaluation. Int. J. Biol. Macromol. 2019, 128, 839-847. [CrossRef]

62. Abdallah, Y.; Ogunyemi, S.O.; Abdelazez, A.; Zhang, M.; Hong, X.; Ibrahim, E.; Hossain, A.; Fouad, H.; Li, B.; Chen, J. The Green Synthesis of MgO Nano-Flowers Using Rosmarinus officinalis L. (Rosemary) and the Antibacterial Activities against Xanthomonas oryzae pv. oryzae. BioMed Res. Int. 2019, 2019, 5620989. [CrossRef] 
63. Jhansi, K.; Jayarambabu, N.; Reddy, K.P.; Reddy, N.M.; Suvarna, R.P.; Rao, K.V.; Kumar, V.R.; Rajendar, V. Biosynthesis of MgO nanoparticles using mushroom extract: Effect on peanut (Arachis hypogaea L.) seed germination. 3 Biotech 2017, 7, 263. [CrossRef]

64. Alsharif, S.M.; Salem, S.S.; Abdel-Rahman, M.A.; Fouda, A.; Eid, A.M.; El-Din Hassan, S.; Awad, M.A.; Mohamed, A.A. Multifunctional properties of spherical silver nanoparticles fabricated by different microbial taxa. Heliyon 2020, 6, e03943. [CrossRef]

65. Salem, S.S.; El-Belely, E.F.; Niedbała, G.; Alnoman, M.M.; Hassan, S.E.; Eid, A.M.; Shaheen, T.I.; Elkelish, A.; Fouda, A. Bactericidal and In-Vitro Cytotoxic Efficacy of Silver Nanoparticles (Ag-NPs) Fabricated by Endophytic Actinomycetes and Their Use as Coating for the Textile Fabrics. Nanomaterials 2020, 10, 2082. [CrossRef]

66. Fouda, A.; Hassan, S.E.; Abdo, A.M.; El-Gamal, M.S. Antimicrobial, Antioxidant and Larvicidal Activities of Spherical Silver Nanoparticles Synthesized by Endophytic Streptomyces spp. Biol. Trace Elem. Res. 2020, 195, 707-724. [CrossRef]

67. Fouda, A.; Hassan, S.E.-D.; Saied, E.; Azab, M.S. An eco-friendly approach to textile and tannery wastewater treatment using maghemite nanoparticles ( $\left.\gamma-\mathrm{Fe}_{2} \mathrm{O}_{3}-\mathrm{NPs}\right)$ fabricated by Penicillium expansum strain $(\mathrm{K}-\mathrm{w})$. J. Environ. Chem. Eng. 2021, 9, 104693. [CrossRef]

68. Al-Hazmi, F.; Alnowaiser, F.; Al-Ghamdi, A.A.; Al-Ghamdi, A.A.; Aly, M.M.; Al-Tuwirqi, R.M.; El-Tantawy, F. A new large-scale synthesis of magnesium oxide nanowires: Structural and antibacterial properties. Superlattices Microstruct. 2012, 52, 200-209. [CrossRef]

69. Karthik, K.; Dhanuskodi, S.; Gobinath, C.; Prabukumar, S.; Sivaramakrishnan, S. Fabrication of MgO nanostructures and its efficient photocatalytic, antibacterial and anticancer performance. J. Photochem. Photobiol. B Biol. 2019, 190, 8-20. [CrossRef] [PubMed]

70. Wang, L.; Hu, C.; Shao, L. The antimicrobial activity of nanoparticles: Present situation and prospects for the future. Int. J. Nanomed. 2017, 12, 1227-1249. [CrossRef]

71. Shaikh, S.; Nazam, N.; Rizvi, S.M.D.; Ahmad, K.; Baig, M.H.; Lee, E.J.; Choi, I. Mechanistic Insights into the Antimicrobial Actions of Metallic Nanoparticles and Their Implications for Multidrug Resistance. Int. J. Mol. Sci. 2019, 20, 2468. [CrossRef]

72. Chiddarwar, S. Novel Approaches of Magnesium Oxide Nanoparticles in MIC, MBC, Antibiofilm and Antimicrobial Activities against Bacteria, Yeast and Biofilms. In Proceedings of the MBC, Antibiofilm and Antimicrobial Activities against Bacteria, Yeast and Biofilms, Hyderabad, India, 19 February 2020.

73. Wong, C.W.; Chan, Y.S.; Jeevanandam, J.; Pal, K.; Bechelany, M.; Abd Elkodous, M.; El-Sayyad, G.S. Response Surface Methodology Optimization of Mono-dispersed MgO Nanoparticles Fabricated by Ultrasonic-Assisted Sol-Gel Method for Outstanding Antimicrobial and Antibiofilm Activities. J. Clust. Sci. 2020, 31, 367-389. [CrossRef]

74. Fouda, A.; Salem, S.S.; Wassel, A.R.; Hamza, M.F.; Shaheen, T.I. Optimization of green biosynthesized visible light active $\mathrm{CuO} / \mathrm{ZnO}$ nano-photocatalysts for the degradation of organic methylene blue dye. Heliyon 2020, 6, e04896. [CrossRef]

75. Ye, W.; Liu, H.; Lin, F.; Lin, J.; Zhao, S.; Yang, S.; Hou, J.; Zhou, S.; van der Bruggen, B. High-flux nanofiltration membranes tailored by bio-inspired co-deposition of hydrophilic $\mathrm{g}-\mathrm{C}_{3} \mathrm{~N}_{4}$ nanosheets for enhanced selectivity towards organics and salts Environ. Sci. Nano 2019, 6, 2958-2967. [CrossRef]

76. Fouda, A.; Hassan, S.E.-D.; Saied, E.; Hamza, M.F. Photocatalytic degradation of real textile and tannery effluent using biosynthesized magnesium oxide nanoparticles (MgO-NPs), heavy metal adsorption, phytotoxicity, and antimicrobial activity. J. Environ. Chem. Eng. 2021, 9, 105346. [CrossRef]

77. Kishor, R.; Purchase, D.; Saratale, G.D.; Saratale, R.G.; Ferreira, L.F.R.; Bilal, M.; Chandra, R.; Bharagava, R.N. Ecotoxicological and health concerns of persistent coloring pollutants of textile industry wastewater and treatment approaches for environmental safety. J. Environ. Chem. Eng. 2021, 9, 105012. [CrossRef]

78. Li, S. Combustion synthesis of porous $\mathrm{MgO}$ and its adsorption properties. Int. J. Ind. Chem. 2019, 10, 89-96. [CrossRef]

79. Ilyas, M.; Ahmad, W.; Khan, H.; Yousaf, S.; Yasir, M.; Khan, A. Environmental and health impacts of industrial wastewater effluents in Pakistan: A review. Rev. Environ. Health 2019, 34, 171-186. [CrossRef]

80. Laxmi, V.; Kaushik, G. Toxicity of hexavalent chromium in environment, health threats, and its bioremediation and detoxification from tannery wastewater for environmental safety. In Bioremediation of Industrial Waste for Environmental Safety; Springer: Singapore, 2020; pp. 223-243.

81. Sawalha, H.; Alsharabaty, R.; Sarsour, S.; Al-Jabari, M. Wastewater from leather tanning and processing in Palestine: Characterization and management aspects. J. Environ. Manag. 2019, 251, 109596. [CrossRef]

82. Barnhart, J. Occurrences, uses, and properties of chromium. Regul. Toxicol. Pharmacol. RTP 1997, 26, S3-S7. [CrossRef]

83. Mohanty, K.; Jha, M.; Meikap, B.C.; Biswas, M.N. Removal of chromium (VI) from dilute aqueous solutions by activated carbon developed from Terminalia arjuna nuts activated with zinc chloride. Chem. Eng. Sci. 2005, 60, 3049-3059. [CrossRef]

84. Mahdavi, S.; Jalali, M.; Afkhami, A. Heavy metals removal from aqueous solutions using $\mathrm{TiO}_{2}, \mathrm{MgO}$, and $\mathrm{Al}_{2} \mathrm{O}_{3}$ nanoparticles. Chem. Eng. Commun. 2013, 200, 448-470. [CrossRef]

85. Gusain, R.; Gupta, K.; Joshi, P.; Khatri, O.P. Adsorptive removal and photocatalytic degradation of organic pollutants using metal oxides and their composites: A comprehensive review. Adv. Colloid Interface Sci. 2019, 272, 102009. [CrossRef]

86. Yang, J.; Hou, B.; Wang, J.; Tian, B.; Bi, J.; Wang, N.; Li, X.; Huang, X. Nanomaterials for the Removal of Heavy Metals from Wastewater. Nanomaterials 2019, 9, 424. [CrossRef]

87. Jain, M.; Garg, V.K.; Kadirvelu, K. Equilibrium and kinetic studies for sequestration of Cr(VI) from simulated wastewater using sunflower waste biomass. J. Hazard. Mater. 2009, 171, 328-334. [CrossRef] 
88. Mohan, D.; Pittman, C.U., Jr. Activated carbons and low cost adsorbents for remediation of tri- and hexavalent chromium from water. J. Hazard. Mater. 2006, 137, 762-811. [CrossRef]

89. Jain, M.; Yadav, M.; Kohout, T.; Lahtinen, M.; Garg, V.K.; Sillanpää, M. Development of iron oxide/activated carbon nanoparticle composite for the removal of $\mathrm{Cr}(\mathrm{VI}), \mathrm{Cu}(\mathrm{II})$ and $\mathrm{Cd}(\mathrm{II})$ ions from aqueous solution. Water Resour. Ind. 2018, 20, 54-74. [CrossRef]

90. Hashem, A.H.; Saied, E.; Hasanin, M.S. Green and ecofriendly bio-removal of methylene blue dye from aqueous solution using biologically activated banana peel waste. Sustain. Chem. Pharm. 2020, 18, 100333. [CrossRef]

91. Fouda, A.; Abdel-Maksoud, G.; Abdel-Rahman, M.A.; Salem, S.S.; Hassan, S.E.-D.; El-Sadany, M.A.-H. Eco-friendly approach utilizing green synthesized nanoparticles for paper conservation against microbes involved in biodeterioration of archaeological manuscript. Int. Biodeterior. Biodegrad. 2019, 142, 160-169. [CrossRef]

92. Essien, E.R.; Atasie, V.N.; Okeafor, A.O.; Nwude, D.O. Biogenic synthesis of magnesium oxide nanoparticles using Manihot esculenta (Crantz) leaf extract. Int. Nano Lett. 2020, 10, 43-48. [CrossRef]

93. Fouda, A.; El-Din Hassan, S.; Salem, S.S.; Shaheen, T.I. In-Vitro cytotoxicity, antibacterial, and UV protection properties of the biosynthesized Zinc oxide nanoparticles for medical textile applications. Microb. Pathog. 2018, 125, 252-261. [CrossRef]

94. El-Belely, E.F.; Farag, M.M.S.; Said, H.A.; Amin, A.S.; Azab, E.; Gobouri, A.A.; Fouda, A. Green Synthesis of Zinc Oxide Nanoparticles (ZnO-NPs) Using Arthrospira platensis (Class: Cyanophyceae) and Evaluation of their Biomedical Activities. Nanomaterials 2021, 11, 95. [CrossRef]

95. Oladipo, A.A.; Adeleye, O.J.; Oladipo, A.S.; Aleshinloye, A.O. Bio-derived MgO nanopowders for BOD and COD reduction from tannery wastewater. J. Water Process Eng. 2017, 16, 142-148. [CrossRef] 